\title{
Kants Kategorientafel und der systematische Begriff der Philosophie.
}

Von Hans Ehronberg.

In der systematischen Philosophie unserer Zeit arbeiten sich zwei Tendenzen entgegen: einerseits fühlt sich das Denken za Leistungen befähigt und will das Recht der Gegenwart in Eigenheit und Leben ausüben, andererseits kann es sich, wenigstens von Zeit zu Zeit, nicht verhehlen, dass seine vermeintlich origonalen Gedanken jedesmal auf Ideen der deutschen Philosophenschule zurückgeführt werden können; so giebt uns die Geschichte, an die wir um der Gegenwart willen appeliert haben, um der Vergangenheit willen Unrecht. Es ist das wohl eine der unangenehmsten Situationen, in der sich die Philosophie je befunden hat. Sie hat nur zwei Wege vor sich: entweder entwickelt sie sich am eigenen Gedanken und muss hernach die Erfahrung machen, dass sie die Mühe der eigenen Arbeit nur auf Gedanken verwandt hat, die andere schon vor hundert Jahren ausgesprochen haben, und dass sie hierbei die ungewollten Vorbilder an Breite und Tiefe nicht einmal erreicht hat. Oder sie sieht ihre Aufgabe darin, sich selbst eine historische Stellung im Verhältnis zu Kant und seinen Nachfolgern $\mathrm{zu}$ erwerben, verliert dann aber nur zu schnell, versunken in den Reichtum dieser historischen Gestaltungen, die Möglichkeit zum selbständigen Produzieren. Während sonst die Philosophie stets durch die Geschichte zur Selbständigkeit und durch die eigene Produktion zu einer geschichtlichen Stellung geführt wird, fehlt uns heute die effektive Gemeinschaft zwischen systematischem Denken und historischem Forschen, und die Philosophie gleicht einem Reisenden, der im fremden Wunderlande wandert und träumt, solange bis er nur noch im Traume nach Hause zurückkehrt. Der folgende Aufsatz weiss sich von diesem Mangel der Zeit nicht frei und unterscheidet sich nur insofern von dem philosophischen Zeitbewusstsein, als er eigene Gedanken 
durchaus bewusst an eine historisch gegebene Gestalt anknüpft und von ihnen am Ende wieder zum Geschichtlichen zurückkehrt.

Das aus der Geschichte Überlieferte, das mir als künstlicher Anfang dient, ist die Kategorientafel Kants. Die zahlreichen Angriffe, die sich von jeher auf sie richten und denen zum Trotz sie sich unverwüstlich zeigt, richten sich wesentlich gegen alles an ihr, sowohl ihren Inhalt als ihre Ableitung. Am Inhalt vermisst der eine irgend eine Kategorie, der andere findet etliche überflüssig; doch ist bei allen diesen „Meinungen" nichts Positives herausgekommen. Es ist überhaupt eine unmögliche Aufgabe, einzelne Kategorien aus der Tafel herauszureissen und für sich zu rechtfertigen oder zu verwerfen. Die inhaltliche Begrenzung der Kategorientafel lässt sich nur zusammen mit ihrer philosophischen Ableitung entwickeln (Übrigens bemerkt man bald die innere Haltlosigkeit solcher rapsodischen Angriffe, auf die hier in entgegengesetzten Sinne einmal ebenso rapsodisch hingewiesen werden mag; Was soll z. B. fehlen? die Kategorie des Zweckes, heisst es; das gilt aber nur von der Kritik des Erfahrungswissens, während der Zweck in Kants Ethik sogar als einzige Kategorie fungiert; wie er ferner die Historie der Organismen (Kritik der teleologischen Urteilskraft) und ebenso die Weltgeschichte beherrscht, ist bekannt genug: es bleibt also, dass der Zweckbegriff nicht in der reinen Naturwissenschaft (Grundsätzen der Vernunftkritik) vorkommt; da wir aber die Succession der Objekte in der Zeit nicht derart erfahren können, dass das Spätere das Frühere bedingt, so würdigen wir die Motive Kants und finden ihn gegenüber jenem Einwand gerechtfertigt. Eine andere Behauptung betrifft das doppelte Vorkommen des Wirklichkeitsbegriffes in der Kategorientafel: Realität und Dasein; nun giebt aber die Kategorie der Realität bei Kant ein Gesetz für die Natur (das Objekt), die des Daseins eine Beurteilungsnorm für das Subjekt; jene bedeutet Inhaltswirklichkeit, diese Tatsächlichkeit (Soundnichtanderssein), zwei Begriffe, die niemand mehr für gleichbedeutend halten wird. Auch die-Kategorien der Wechselwirkung und der Limitation sind nicht unbehelligt geblieben; wenn wir aber anstatt jener - Gemeinschaft sagen, an Stelle dieser: durch Aussage über das, was es nicht ist, bestimmtes Sein, so sind diese Kategorien ebensogut gerechtfertigt. In Summa zeigt sich hierin, dass auf so simple Denkweise Kategorien weder zu erzeugen noch umzubringen sind). 
Ich wende mich deshalb zur Frage der Ableitung oder Deduktion der Kategorientafel. Im Rahmen der Vernunftkritik, also unmittelbar vom Standpunkt Kants, sehe ich für diese Deduktion drei Möglichkeiten: die Ableitung aus den Urteilsformen (Kant), die aus der transscendentalen Apperzeption (Fichte), die ans den Grundsătzen (Cohen, Stadler). Das Verhältnis der Kategorien zu den Urteilsformen einer-, den Grundsätzen andererseits soll uns zuerst beschäftigen. Man sieht es entweder so an, als ob die Urteilsformen und Grundsätze von den Kategorien bezogen seien, womit sicher nichts für die Deduktion der Kategorien gewonnen wäre, oder man glaubt ausdrücklich, die Kategorien für das logisch Spätere halten zu dürfen; folgendes lässt sich für das Letztere sagen: Urteile sind nötig, um irgend einer Kategorie Anwendung zu geben, erst im Urteilen verschafft uns die Kategorie ein Wissen. Die Urteile aber, in denen irgend ein Wissen ausgesprochen wird, lassen sich sowohl formallogisch als auch transscendentallogisch ansehen, d. h. erstens nach den analytischen Urteilsformen, zweitens nach den synthetischen Urteilsformen (synthetischen Urteilen a priori oder Grundsätzen). Es besteht also zwischen der eigenen Ansicht Kants, der die Kategorien aus den Urteilen gewinnen zu können glaubte, und der besonders unter Neukantianern vertretenen Ansicht einer Deduktion der Kategorien aus den Grundsätzen das Gemeinsame, dass die Anwendung der Kategorie das Kriterium für ihre jeweilige Inhaltsbestimmung abgeben soll. Wie verhält es sich nun mit einer solchen Deduktion? Kann man nicht zu Gunsten jener Ansicht anführen, dass die Kategorie ihrem Begriff nach den in einer Erfahrung anzuwendenden Verstandesbegriff bedeutet, dass die „transscendentale Bedeutung“ derselben nur als Moment der "empirischen Anwendung“, d. h. als in einem Urteil enthalten, gewiss wäre? Aber damit wird doch keine Kategorie ihrem inhaltlichen Sinn nach entwickelt. Wenn vielmehr in Wahrheit ein inhaltliches Deduzieren geschehen soll, das mehr als den blossen Begriff - überhaupt der Kategorie ergiebt, so muss ein Masstab da sein, durch dessen Benutzung wir in den Stand gesetzt werden, entweder die Tafel der Urteile-oder die der Grundsätze Vollkommen zu finden. Wenn es aber der Vorzug der Philosophie ist, sich nirgends einem fremden Masstab fügen zu brauchen, ja nicht einmal zu dürfen, ohne dadurch in den Relativismus zu verfallen, so kann auch die Deduktion einer Kategorientafel gar nicht mit Hilfe eines fremden Masstabes stattfinden, 
sondern muss in ihren eigenen Begriff den Masstab für ihre Ausführung besitzen. (So ist es z. B. der eigene Begriff des Verstandes (Begriff einer möglichen Erfahrung), an dem die Vernunft die Grenzen des Verstandes gebrauchs in der Vernunftkritik bestimmt (Kr. d. r. V., 400)). Um also die Tafel der Urteilsformen oder die der Grundsätze als Ausgangspunkt für die Deduktion der Kategorien ansehen zu können, müsste die eine oder andere durch ihren eigenen Begriff in ihrem Umfang und Inhalt bestimmt werden können.

Wie solte aber die formale Logik einen Masstab haben, an dem sie sich selbst messen kann, da sie von aller gegenständlichen Bedeutung, sei es der Erfahrung, sei es der Idee, abstrahiert hat, also weder einen Anfang noch ein Ende noch einen Fortgang von einem Teil zum anderen, es mithin gar keinen Begriff eines Systems derselben geben kann. Das kastrierte Denken der formalen Logik ist noch nicht einmal fähig gewesen, sich in der Geschichte zu entwickeln; es hat seit Aristoteles keinen Schritt vorwärts gemacht!

In ganz anderer Wertschätzung müssen uns die Grundsätze stehen; sie sind im Gegensatz zur formalen Logik wenigstens ein Bestandteil der Philosophie. Aber sie sind doch nur eine Wissenschaft von der Natur. Wie kann aber die Naturphilosophie (reine Naturwissenschaft) einen Masstab besitzen, der sich auf die Kategorien beziehen liesse? Und wenn die Naturphilosophie allerdings mit einem eindeutigen Anfang beginnt, nämlich dem Begriff des Mannigfaltigen, und von ihm aus gleichsam die logische Schöpfungsgeschichte der Natur entwickelt, so liegt doch deren Endpunkt nicht bereits in dem philosophischen Begriff der Natur, und die Schöpfung würde aus sich heraus nie Halt machen, wenn es ihr nicht die bereits gezogenen Grenzen einer Kategorientafel geboten. Nur empirisch können wir die vor unserem Denken transscendental entstandene Welt mit der uns aus der Erfahrung bekannten vergleichen; doch kann derartiges Vergleichen nie als etwas Endgültiges angesehen werden; denn es bliebe doch stets das: es könnte auch anders sein - - , (und die Einwände des Positivismus gröberer wie feinerer Schattierung gegen die "Unverwüstlichkeit" der Kategorien würden im Rechte sein). In der Kritik als Philosophie der Erfahrung, d. h. als reiner Naturwissenschaft, ist daher gar kein Platz für eine ausgeführte Kategorientafeldeduktion, und damit noch nicht einmal für das Problem derselben. - Hier möchte ich überhaupt die Bemerkung machen, dass man zu sehr 
geneigt ist, in der Kritik der reinen Vernunft mehr als Naturphilosophie zu sehen, während sie, wenigstens ihren Ergebnissen nach, nirgends etwas anderes behandelt, als die Welt der Erscheinungen, die Sinnenwelt. Es wird, wenn man sich dies zur Genüge vorgestellt hat, nicht verwunderlich erscheinen, dass Kant in der 2. Aufl. selbst zur Einsicht gekommen ist, dasjenige, was wir heutzutage unter einer Deduktion der Kategorientafel verstehen würden, auch als Aufgabe von sich abzuweisen; er sagt: „Von der Eigentümlichkeit unseres Verstandes aber, nur vermittelst der Kategorien und nur gerade durch diese Zahl und Art derselben Einheit der Apperzeption a priori zu Stande zu bringen, lässt sich ebensowenig ein Grund angeben, als warum wir gerade diese und keine andere Funktionen zu urteilen haben, oder warum Zeit und Raum die einzigen Formen unserer möglichen Anschauung sind" (Kr. d. r. V., 668). Möchten wir heute auch in den von Kant abgelehnten Aufgaben notwendige Inhalte der Philosophie sehen, so können wir doch darin nicht von ihm abweichen, dass wir sie nicht zur Erkenntnistheorie der Natur zu rechnen haben.

Wenn wir aber gleichwohl die Frage nach einer ernsthaften Deduktion der Kategorientafel erheben, so muss derselbe in einem Punkte mit dem ursprünglichen Versuche Kants übereinstimmen, nämlich in der Ableitung aus einem anderen bereits als Vielheit gegliederten System von philosophischen Begriffen. Hierbei würde sich die weitere F'rage erheben, ob wir unter dem die Kategorientafel hervorbringenden System die Philosophie im allgemeinen und ganzen oder ein System speziell der reinen Logik zu denken haben. Im letzteren Falle würde sich durch den $\mathrm{Zu}$ sammenhang von Kategorie zu Kategorie innerhalb der Kategorienlehre selbst der systematische Begriff entwickeln, durch den ebenso wie der Fortgang von einem Kategoriebegriff zum anderen auch der Anfang und das Ende der Tafel bestimmt würde. Fichte hat zuerst diesen Versuch gemacht, nur dass bei ihm die Kategorien noch die Zweideutigkeit an sich haben, dass ihr System, d. i. die Wissenschaftslehre, zugleich reine Logik (Entwicklung des Ich) wie Erkenntnistheorie (Naturphilosophie) giebt; um diese Doppeldeutigkeit zu vermeiden, sieht man sich bei Fichte auf die Einheit des Prinzips (Identität des Ich) zurückversetzt, welches aber auch Kant schon besass, sodass auch Fichte noch der von ihm selbst gegen Kant erhobene Vorwurf gebührt, die Vielheit der Kategorien aus der Einheit des Kategoriebegriffes ohne systema- 
tische Notwendigkeit abgeleitet zu haben; erst Hegel hat durch seine systematische Denkweise den inneren Widerspruch der Kantisch-Fichtischen Philosophie beseitigt, indem er Logik und Naturphilosophie trennt. Es ist daher sehr bezeichnend. dass Hegel sich in der Einleitung zu seiner Logik auf Kants Begriff einer transscendentalen Logik beruft und doch in der Tat statt einer Kritik der reinen Vernunft (als Theorie der Erfahrung) ein System der Denkformen des Philosophierens selbst giebt. Aber darin liegt auch der innere Widerspruch seiner Logik, dass die Kategorien einen Gehalt haben sollen und trotzdem ihre Inhaltsbedeutung von allen bestimmten philosophischen Disziplininhalten entblösst ist. Es lässt sich aber nicht einsehen, wie man innerhalb der Philosophie von philosophischen Begriffen Gattungsbegriffe bilden kann, ohne dadurch in die rein formale Logik zurückzufallen. Wenn es nun gewiss ist, dass die Logik Hegels von einer formalen Logik am weitesten entfernt ist, so nimmt sie dafür aber die Unklarheit in den Kauf, dass jede ihrer Kategorien in sehr verschiedenem Sinne verstanden werden kann, je nachdem man sie auf einen Natur-, Sittlichkeits-, Kunst- u. s. w. Begriff bezogen denkt. Es frägt sich also, ob die einzelne Kategorie ohne einen bestimmtem ausserhalb der Kategorie liegenden Inhalt noch philosophische Objektivität (Wahrheit) besitzen kann, zumal wenn die Kategorienlehre am Anfang des Systems steht und die anderen Begriffe, auf die sich die Kategorien potentiell beziehen, noch gar nicht entwickelt sind. Dieses Bedenken gegen die Logik Hegels führt mich auf den Gedanken, die Kategorientafel im konkreten Zusammenhang mit den Inhalten der philosophischen Disziplinen zu deduzieren. Dieser Versuch ist noch nicht gemacht, und ich glaube daher, dass es auch für denjenigen, der von vornherein ein Misstrauen gegen ihn hat, nützlich sein wird, ihn durchzudenken. Denn da wir doch einmal erkannt haben, dass die Philosophie Kants keine Deduktion einer Kategorientafel enthält, ja nicht enthalten kann, ist es die wichtigste Aufgabe der Philosophie geworden, das Verhältnis von Logik und Philosophie gedanklich zu durchdringen.

Es ist hier auch der Ort, in einem neuen Sinne auf eine vielbemerkte Eigentümlichkeit der Kantischen Systematik hinzuweisen. Der innere Aufbau seiner Werke, zum Schaden der Philosophie stets nur mit überlegenem Spott oder philologischer Akribie behandelt, läuft oft, wie Kant sich ausdrückt, „am Leit- 
faden der Kategorientafel ${ }^{\text {. }}$. So folgt die Systematik der Antinomien, der Metaphysik der Natar, der Analytik des Schőnen, der Reihenfolge der Kategoriengruppen Quantităt, Qualităt, Relation und Mrodalität, die der Religion innerhalb der Grenzen der Vernunft disponiert ihre vier Teile nach Qualität, Quantität u. s. w. (wie oben). Ohne auf die einzelnen Beispiele einzugehen, müssen wir doch streng zwei verschiedene Gruppen unter ihnen unterscheiden; Die Disposition der Antinomienlehre oder der Metaphysik der Natur nach den vier Kategoriengruppen hat darin ihren Grund, dass jene wie diese die Kategorien als transscendentale Grundsätze der Erfahrung voraussetzen; sie sind philosophische Umbildungen des Systems der reinen Naturwissenschaft; die Systematik an Hand der Kategorien folgt daher hier aus der inhaltlichen Anwendung derselben; sie stehen hier auch in der Bedeutung des Erfahrungsgebrauchs, sind Begriffe von einem Gegenstand der Sinnenwelt, und auch ihre Bedeutung für die Systematik erschöpft sich so in dem Erfahrungsgebrauch. Dagegen hat weder die Philosophie des Schönen noch die der Religion ein begriffliches Verhältnis zu den. Naturkategorien; vielfach ist daher gerade für sie die Meinung verbreitet, dass hier Kant seine Systematik einem einmal erprobteu Denkschema zu Liebe gebildet habe. In der Tat aber fungieren die Kategorien hier in dem Sinne, nicht Objekte der Sinnenwelt, sondern der Ideenresp. Wertwelt zu konstituieren; um nur ein Beispiel zu nennen, so wird die Quantität selbst ein Bestandteil des Schönheitswertes: ästhetischer Gemeinsinn. Die Kategorie ist dann nicht der Begriff eines Objektes, sondern einer Idee -, der Gebrauch der Kategorie ist kein empirischer, sondern ein absoluter. Eben diesen Begriff einer absoluten Anwendung der Kategorien ist es nun, den ich im folgenden einer versuchsweisen Ausführung unterwerfen will - und sowenig Kant einer solchen Behandlung zugestimmt hätte, so sehr liegen doch die Keime $\mathrm{zu}$ ihr in ihm selbst.

Ich werde also im Folgenden die Philosophie als ein System von reinen Begriffen (Vernunftideen bei Kant, absoluten Werten bei den Modernen) darstellen. Das System ist das Kants, das in seiner schliesslichen Gestaltung in theoretische, praktische, ästhetische und Religionsphilosophie zerfiel. Auch hier folge ich also dem historisch Gegebenen, mit dem Bewusstsein, damit an das Wertvollste, das wir besitzen, anzukniipfen - und werde nur die Philosophie der Kunst, übrigens im Anschluss an gewisse Be- 
merkungen Kants, mit der theoretischen Philosophie in einem Teile des Systems vereinen; die Begründung dafür findet sich an der betreffenden Stelle.

Ich beginne mit der Ethik; der Grund ist der, dass allein von ihr im Kantischen System gilt, dass sie keinerlei Voraussetzungen macht; Kant nennt daher den Begriff der Freiheit ndie einzige unter allen Ideen der reinen Vernunft, deren Gegenstand Tatsache ist, und unter die Scibilia mit gerechnet werden muss“ (Kr. d. Urt., 370); es ist dies der Grund, warum Kant dem reinen Vermögen der praktischen Vernunft zugesteht, sich durch die Tat zu realisieren und einer besonderen Deduktion im Sinne seiner Methode entbehren zu dürfen; es ist daher nicht wiederum Gegenstand einer kritischen Überlegung (Kr. d. pr. V., 1). Der Begriff der Freiheit macht deshalb, nach Kant, den Schlussstein (ebenda) von dem ganzen Gebäude eines Systems der reinen, selbst der spekulativen Vernunft aus, und alle anderen Ideen werden als möglich nur dadurch bewiesen, dass Freiheit wirklich ist. In Ansehung der Freiheitsidee kann man sagen, hört die Kritik auf, Kritik zu sein. Bei ihr liegt der voraussetzungslose Anfang des Kantischen Philosophierens; denn Freiheit setzt ausser sich selbst nichts voraus; sie hat geradezu die Bedeutung des. Begriffes „Keine Voraussetzung“. Es ist dies meines Erachtens die wahre Bedeutung, die man Kants Lehre vom Primat der praktischen Vernunft geben muss, wenn man sie als einen Begriff fassen will, der über dem Inhalt der einzelnen Kritiken stehen soll. (Hegel hat zuerst von der Philosophie verlangt, dass sie mit einem Begriff beginne, der sich selbst als Anfang der Philosophie rechtfertige; dies wäre aber nicht, wie Hegel selbst meint, der Begriff des Anfangs, welcher vielmehr in einen viel späteren Teil des Systems, in die Philosophie des philosophischen Denkens, gehört, sondern es ist dasjenige, dessen begrifflicher Sinn ist, ein Anfang zu sein, d. h. dasjenige, das die Bedeutung des Anfangs hat; das ist aber die Freiheit, in deren Begriff es liegt, jedes philosophische A priori ihrer selbst auszuschliessen (cf. auch bei Kant: Freiheit $=$ absoluter Anfang einer Reihe). In diesem Sinne nehme ich den Gedanken Fichtes von der Freiheit als ursprünglicher Tathandlung auf).

Hier ist folgende, ein wenig komplizierte Überlegung $\mathbf{z u}$ machen:- Die Freiheit ist der Anfang -, aber der Begriff des Anfangs setzt etwas Folgendes, wofür es Anfang ist; die Frei- 
heit ist somit sowohl das absolute Anfangen als das absolut Angefangene; dieses ist also dasjenige, wo für die Freiheit ist; wenn aber die Freiheit etwas hat, für das sie ist, so hat sie einen Zweck; dieser ist das Angefangene (für das sie frei ist, um es auzufangen). Der Zweck der Freiheit ist somit das Anfangen; aber nur in Beziehung auf das Anfangen kann ich von einem Zweck der Freiheit sprechen; dieser ist also selbst durch das Anfangen bedingt, d. h. der Zweck der Freiheit wurzelt so selbst wieder in dem Zweck, den das Anfangen hat; also ist das Anfangen sowohl Freiheit als der Zweck der Freiheit, oder Freiheit und Zweck der Freiheit sind identisch, d. h. die Freiheit ist sich selbst Zweck.

Der Zweck ist aber stets ein Bezwecktes, ein anderes, das gewollt wird; wenn es heisst, dass die Freiheit sich selbst Zweck ist, so unterscheidet sie in sich sich selbst als Zwecksetzendes und als Bezwecktes: als ersteres ist sie die Freiheit als der Wille, der frei ist, und als letzteres ist sie das Objekt des freien Willens, das Kant das Reich der Zwecke nennt. Das Reich der Zwecke aber ist nicht inhaltlich bestimmbar; es verdient ebenso das Reich der Freiheit zu heissen; seine Zwecke sind nur negativ bestimmt als von anderen Bestimmungsgründen freie $Z$ wecke. Der Wille, der das Reich der Zwecke will, ist als solcher der Wille, welcher von ausser ihm liegenden Gründen frei ist; in dieser Negation ist gerade seine positive Wesenheit enthalten; er ist der nicht-bestimmte Wille, oder die Freiheit ist in inm als absolute Negativität des Wollens, d. i. als Heiligkeit. (Die Kategorie der Limitation dient uns dazu, ihn in seiner Wahrheit zu erkennen (der Satz hat deshalb die Form des der Limitation bei Kant korrespondierenden unendlichen Urteils: A ist non-B). Der heilige Wille ist mithin als Negation der Negation, d. h. durch Verneinung Bejahtes, der Stammbegriff des Systems der Sittlichkeit).

Der qualitativ reine Wille des Heiligen lebt in der reinen Intelligibilität; in ihm liegt durchaus noch die Unbestimmtheit darüber, was für Inhalte er als Zwecke will; er kennt nun nichts als sich selbst, und so muss er sich selbst auch als einziger Zweck anerkennen; dann bleibt er aber in seinen Zwecksetzungen bei sich selbst, und statt der. Welt, welche er aus sich erschaffen wollte, entsteht ihm inmer nur das eigene Selbst wieder und wieder. Der heilige Wille verneint so die Wirklichkeit seiner 
Wirksamkeit: Wenn die Freiheit ihrem Begriff nach - sie giebt sich sich selbst als Selbstzweck - an sich selbst ihre Realität hatte, so zeigt sich jetzt im Gegenteil, dass sie im Verwirklichen ihrer selbst, d. h. in der Ausführung ihrer Zwecksetzungen, nicht zur Wirklichkeit kommt; sie verneint sich der Realität nach, das Reich der Zwecke kommt nicht zu Stande, und der Wille ist so überhaupt zum Schweigen gebracht, zur Untätigkeit verurteilt; er ist die Freiheit, die Nichts ist, d. i. aber das Unheilige, das Böse, der Geist, der stets verneint.

Aber weiter ergiebt sich, dass der Wille, der seine Realität verneint (weil er in der Zwecksetzung, in der er zur Wirklichkeit kommen will, immer wieder zu sich selbst zurückkehrt), dass dieser böse Wille im Sich-selbst-wollen einen Inhalt hat, nämlich sein Ich, dem er treu bleibt, den er bejaht; und in der Konsequenz, mit der er sich zu sich selbst bekennt, macht er sich zur Persönlichkeit, und sein Wille ist das Gute, in ihm produziert die Freiheit wirklich, und er hat die Realität in sich. Das Gute ist also das Ich, insofern es sich selbst treu bleibt; hierin verhält es sich zu sich selbst und hat den Grund seines Willens unvermittelt in sich; das Ich aber als sich selbst Bestimmendes ist frei, d. i. der Wille als der freie Wille des Ichs, als seine autonome Sichselbstbestimmung, ist sein Gutsein. Aber insofern er nur sich selbst will, verwirklicht sich der gute Wille nicht und ist so wiederum der böse, und so gehen gut und böse noch in einander über; das Sichtreubleiben von der Seite des Wollens ist das Gute, von der Seite des Gewollten aber das Böse; der gute Mensch, der bei sich bleibt, will so das Gute, aber unter der Hand wird es ihm zam Bösen, weil ihm überhaupt Nichts aus seinem Willen entsteht - der böse Mensch, der sich konsequent bleibt, will so das Böse, aber unter der Hand wird es ihm zum Guten, weil er als Persönlichkeit will - das Ich ist somit ebenso gut wie böse, es ist beides. Somit steht es ausserhalb des Guten, um böse, und ausserhalb des Bösen, um gut sein zu können; d. h. das Gute und Böse haben die Bedeutung des sittlichen + (gut) und des sittlichen - (böse) (Kant), das zum Ich hinzugesetzt wird, d. i. die seines sittlichen Wertes. Damit treten Gut und Böse auf dieselbe Seite des Gegensatzes; Ich und sittlicher Wert, und ihr wechselseitiges Ineinanderübergehen wird so begriffen. Allein im Guten und Bösen erhält das Ich seine sittliche Wertbestimmung, und allein in der Beziehung auf diese existiert es auf dieser Stufe 
der Philosophie; das Ich ist somit das sich zum Guten wie Bösen verhaltende Ich; das Gute ist gerade ihm das +, das Böse gerade ihm das -, es erkennt das Gute an, verwirft das Böse - für sich selbst erkennt es an, für sich selbst verwirft es, denn das Gute und das Böse sind nur seine eigenen Werte. IVas es bewertet, ist somit seine eigene Bestimmung (Bestimmung des Menschen). - - Oder das Gute und Böse verbalten sich $\mathbf{z u}$ ihm als Negation seiner Freiheit, als Gesetz. (Die Freiheit steht noch jenseits von gut und böse, in der Freiheit ist das Gute noch ebensosehr das Böse und das Böse ebensosehr das Gute; für den, der ,jenseits von gut und böse" urteilt, muss, wie sich ergab, so alles Positive für gut, alles Unproduktive für böse gelten; aber ihre wahrhaft ethische Bedeutung erhalten gut und böse erst am Begriff des Gesetzes. Das Heilige ist für uns daher nur das sittliche Ideal, gut und böse aber die sichtbaren Masstäbe, und der Unterschied des Göttlichen und Menschlichen ist in der Moral ein qualitativer: er liegt in der fleckenlosen Reinheit der Gesinnung. Erst für ein. Wesen, dem das Sittliche nicht Natur, sondern Gebot ist, giebt es die Wahl zwischen gut und böse. Das Gesetz aber ist das Anderssein der Freiheit, es setzt die Freiheit als Bestimmungsgrund voraus, verneint sie aber in sich selbst; im Gesetz wird so die Freiheit aus sich heraus zum Inhalt, zur Wirklichkeit kommen. Das Gesetz aber steht diesseits von gut und böse und hat die beiden hinter sich, ist aber wegen dieses Dualismus noch nicht die unmittelbare Wirklichkeit des Sittlichen; es setzt vielmehr das Wirkliche als Vermittlung für sich voraus, durch dass es entweder bejaht oder verneint, und so realisiert wird; d. h. das Gesetz ist nicht selbst eine sittliche oder unsittliche Realität, sondern zu ihm verbält sich etwas, für das es als Masstab der Sittlichkeit dient: das Gesetz ist nur die Norm, das Nur-gesollte, und zu ihm verhält sich das Sein als erfüllend oder nicht erfüllend).

So finden wir uns, indem wir den Widerspruch der guten und der bösen Freiheit gelöst haben, in einen neuen Widerspruch verstrickt: das Gesetz giebt nur ein Soll, und der Norm tritt die Wirklichkeit des Subjekts als ein ihr Fremdes gegenüber; das Gesollte ist nämlich das Noch-nicht-seiende, und das Seiende ist als Seiendes das Nicht-mehr-gesollte. Aber wie wäre das Gesetz Gebot, wenn es nicht gesetzt wäre? wie gesetzt, wenn es dadurch nicht das Sein in sich enthielte? Das Sollen schlägt somit in 
seinen Gegensatz, die Macht des Seins, unr, und ebenso bringt das Sein das Sollen in sich hervor; nämlich nur als Nicht-sollen ward uns der Begriff des Seins, aber damit ist es eben des Sollens Seins. Dasjenige, was, weil es ist, nicht mehr gesollt wird, ist gerade das Gesollte selbst, und dasjenige, was noch nicht ist, ist nichts anderes als das Sein des Sollens. Diesem Ineinanderübergehen von Sein und Sollen wird der Begriff des Gewissens gerecht; in ihm, als dem Bewusstsein des Verpflichtetseins, lebt das Soll als anerkannter kategorischer Imperativ sein Sein, und das Gewissen ist andererseits ein Seiendes, das nur solange ist, als es das Bewusstsein der Pflicht, des Sollens ausspricht. In der inneren Stimme kommt so das Ich zu seiner sittlichen Wirklichkeit; denn im sittlichen Ich (Gewissen) liegt es, im Selbstbewusstsein die Einheit des Sollens als Sollen mit demselben als Sein zu vollziehen, und nicht anders die Einheit des Seins als Sein mit demselben als Sollen (Selbstbewusstsein und Gewissen).

Wenn wir aber näher zusehen, so bemerken wir eine bedeutsame Wandlung: das Sein wird nicht als Sein gesollt, wohl aber das Sollen als Sollen; das Sollen verlangt nach dem Sein, nicht aber das Sein nach dem Sollen, d. h. das Sein ist für das Sollen, nicht aber das Sollen für das Sein da: im Verhältnis von Sollen und Sein hat das Sollen das Primat. Daher ist das Sollen, das im Gesetz ausgesprochen wird, gar kein Sollen, sondern eben das Sein, nach dem das Sollen verlangt, das ewige Ist, das dem Gesetz zukommen soll, um es wirklich zu machen. Der Inhalt des Sittengesetzes ist somit die Wirklichkeit seiner selbst; das ist es, was durch die Norm geboten wird. Das Sein ist also selbst ein Gesolltes, $d \cdot{ }^{\prime}$. es kommt nicht zum Sein, sondern bleibt selbst im Sollen.

Der Inhalt des Sollens ist somit selbst nur das Sollen, oder das Gesetz hat nur sich selbst zum Inhalt; das ist der kategorische Imperativ (Gesetz der Gesetzmässigkeit). Das Gesetz der Gesetzmässigkeit findet nicht seine Realisierung, sondern hat sie nur in seinem Begriff. (Aber ebendeshalb ist das Sittengesetz, der kategorische Imperativ, das leere Gebot; an der Hand der Anerkennung des Sittengesetzes machte die Wirklichkeit ihren ersten Schritt im Dasein, aber es zeigt sich, dass sie noch nicht allein gehen kann; für sich ist das Sittliche noch das Gesetz schlechthin, ohne inhaltliche Bestimmung; sobald das Gewissen es 
loslüsst, fällt es um. Dem Sittengesetz, das sich nur auf das Ich-ïberhaupt bezieht, ist auch jeder recht, und so wälzt der eine die Erfüllung des Gebotes, gut za sein, auf den anderen ab und so fort. Dor kategorische Imperativ hat also in sich den Widerspruch, ein Sein des Solles sein zu wollen, und docb nur Gebotïberhaupt zu bedeuten; und das Sollen, dem das Sein beiwohnt, besitzt es in der Anerkennung durch das Selbstbewusstsein, und doch ist die Anerkennung nur die Gesinunng-überhaupt, und das Gesetz weiss nicht, an wen es sich mit seiner Forderung halten soll. Dies hat man wohl schon gefunden, dass das Sollen und das Sein im Sittengesetz in einander übergehen, aber man hat geglaubt, deshalb es verwerfen zu müssen, anstatt die Wahrheit in dem Erkannten zu bemerken: dass die absolute Pflicht eben das Allgemeine, Inhaltslose ist, welches noch nicht dem Sollen eine Wirklichkeit verschafft und keiner Wirklichkeit ihren sittlichen Wert. In einer Phänomenologie des Bewusstseins würde der kategorische Imperativ daher den Sinn haben, dass das Individuum sich an sich selbst verliert: es realisiert das Sollen bereits in seinem reinen Wollen, aber mit der Realisation ist es ihm bereits ein $\mathrm{zu}$ Überwindendes geworden, und insofern ist ihm durch das blosse Wollen, d. h. die blosse Versenkung in die eigene Gesinnung, ein neues Sollen entstanden; sein Tun heisst dann sich selbst stets von neuem zu überwinden, und so verliert es sich an die Allgemeinheit seiner selbst.)

Hier entsteht also der Übergang von Kants Begriff der Moralität der Gesinnung zu dem der Legalität der Handlung. Das moralische Gebot ist im Überhauptsein, es entbehrt des Inhalts; das Sein des Gesetzes vollzog sich bis jetzt nur an der Einheit des Gesetzes; aber die Einheit des Sittengesetzes gab diesem als einem Unbestimmten keine Wirklichkeit. Als Gesetz-überhaupt fand es noch nicht seine Wirklichkeit für sich; sondern sie wurde ihm nur im Begriff zugesprochen, sodass es tatsächlich ohne sie war, sobald es sich in sich reflektierte, für sich wurde. Das Sittengesetz ist also als Gesetz unwirklich und hat die Seite seiner Wirklichkeit nur noch im anerkennenden Individuum; das anerkennende Individuum ist damit als es selbst wirklich, d. h. nicht nur als der Begriff des Individuums (Einer-überhaupt), sondern ein tatsächliches Individuum, ein Bestimmter. Aus dem Gegensatz des Sollens und des Seins wird der des allgemeinen Sollens und des besonderen Seins. Das allgemeine Sollen ist das Sitten- 
gesetz -, das besondere Sein ist das anerkennende Ich. Jenes hatte zwar den Begriff des Seins in sich; d. h. wie es das allgemeine Sollen ist, so ist es auch das allgemeine Sein; und ebenso hat jetzt das anerkennende Subjekt die Bestimmtheit des Sollens, welches es anerkennt, an sich, und das besondere Sein ist so das Sein des besonderen Sollens. Wenn Sittengesetz und Sitte sich daher wie Allgemeines und Besonderes verhalten, so ist das Allgemeine die Einheit schlechtweg, welche sich überall, das Besondere aber die Vielheit, welche sich nur im Einmaligen finden lässt. Das Sittengesetz und die Sitte verhalten sich also wie das Eine und das Viele. Es sind vielfache Maximen oder Vorschriften, welche von den Willen vieler Individuen anerkannt werden; der Sitten giebt es unbeschränkt viele, insofern es auch unbeschränkt viele sind, die nach irgend einer Sitte handeln.

Aber an der Sitte hangen die Vielen, welche nicht alle werden; so giebt es immer irgend welche, die nicht zu denen gehören, die nicht alle werden: was die anderen tun, brauche ich nicht zu tun; die Sitte hört daher überhaupt auf, unbedingtes Gesetz für mich zu sein. Das Sittengesetz als Gesetz-überhaupt ist keine Wirklichkeit mehr, die Sitte als die Handlung-überhaupt ist kein Gesetz mehr; sie ist, wie Kant sagt, nur hypothetischer Imperativ, d. h. in Wahrheit überhaupt gar keiner; denn ein Gesetz ohne notwendige Gültigkeit ist kein Gesetz mehr.

Aber indem irgend einer sich ausserhalb irgend einer Sitte stellt, ihr Gebot nicht anerkennt, so wird er dadurch doch nicht an und für sich selbständiges Individuum, sondern hat im Verneinen jener bestimmten Sitte eben seine bestimmte Sitte; keiner steht so ausserhalb der Sitten, sondern alle haben irgend eine Sitte - und der Sittenbekämpfer hat für uns nicht das Interesse einer originellen Persönlichkeit, die er als Sittenbekämpfer vorzustellen meint. (An dem kategorischen Imperativ bemerkten wir den Mangel der Unbestimmtheit, an der Sitte den der Zufälligkeit; die Einheit des Sollens und des Seins ist im Sittengesetz nur dem Begriff nach, in der Sitte nur der Tatsache nach vollzogen; in jenem ist sie an sich, in dieser für sich. Der Unterschied von Sollen und Sein verwandelt sich so in den der Geltung (überhaupt) und des Inhalts (Sosein).)

Indem alle notwendigerweise ihre Sitte haben, entsteht das Recht; in ihm einen sich Gesetz und Sitte. Der Inhalt mit seiner Zufälligkeit erhält den Charaikter der Geltung als Gesetz; die 
Sitte wird im Recht als das Gesetz aller zur Pflicht erhoben. In der Sitte lebt Rousseans volonté de tons (der Wille eines Menschenaggregats), im Recht sein volonté générale (der Wille der Allgemeinheit als Einheit). Die Vielen sind jetzt wahrhaft alle geworden, denn niemand mehr steht ausserhalb des Rechtsgebotes, und die unbestimmte Mehrzahl der Sitten ist ebenfalls bestimmt worden, denn es giebt auf dem Standpankt des Rechts kein anderes Gebot als das des Rechts; alles andere ist erlanbt. Als der Begriff des Sittlichen sich zuerst in ein spezifisch Sittliches (sittlicher Wert) und ein Indifferentes (Ich) dirimierte, ward das Sollen das Sittliche, das Sein das Indifferente; dann war die Geltung-überhaupt das Sittliche, das Sosein das Indifferente; dagegen ist im Recht das Sollen, die Geltung, als Soseiendes, nämlich durch die Gesetzgebung da, und das Soseiende, das historische Recht, ist andererseits unmittelbar Gebot. Das "geltende Recht", wie es der Jurist nennt, ist deshalb das soseiende (wie es jetzt gerade ist), und wie Gelten und Sosein, fallen auch Sollen und Sein beim Recht in Eins. Das Recht ist deshalb, wie man zu sagen pflegt, empirische Norm, d. h. der Gegensatz von Geltung und Sein (Werthaftigkeit und Faktizität) ist in ihm überwunden. Es genügt das blosse Dasein, die Existenz eines gegebenen Gesetzes, um ein Sollen zu begründen. Das Sittliche ist als Sollen im Recht zu dem gekommen, was es suchte, d. i. zu seiner Wirklichkeit. (Vorher war ihm in der reinen Freiheit jede Wirklichkeit versagt gewesen, am Sittengesetz glaubte es sie zu finden, aber es kam dabei über das allgemeine, abstrakte Sein nicht heraus - erst im Recht wird es faktisch wirklich, hat es wirklich seine Wirklichkeit.)

Aber damit hat es aufgehört, eine Wirklichkeit der Freiheit darzustellen; ebenso ist es gegen die Gesinnung gleichgültig geworden, sodass es dem Willen gar nicht mehr die Wahl lässt; das zeigt sich in der Rechtssprechung; das Recht ist in ihr der Zwang, die Nichtfreiheit. Gleichwohl ist es durch freie Rechtsschöpfung entstanden; das Recht hat so die zwei Seiten, erstens die der Gesetzgebung als die seiner Freiheit und zweitens die der Rechtssprechung als die seiner Unfreiheit. Das Recht ist daher ebenso wirkliche Negation der Freiheit (welche im Sittengesetz nur dem Begriff nach negiert war), als es auch Freiheit ist, widrigenfalls es im System der Sittlichkeit gar keinen Platz hättte. Im Recht ist also der erste Teil der Sittlichkeit, die Freiheit, 
und sein zweiter, das Gesetz, zu ihrem unzweideutigen Widerspruch gelangt. Wir stehen deshalb am Übergang zum dritten Teil, dem Gesetz der. Freiheit, indem der Gegensatz der beiden ersten seine Aufhebung und Anerkennung zugleich erfährt. Es gleicht das Recht dem Planeten, der sich ewig um die Sonne der Freiheit bewegt; er will ihr zufliegen, wie er einstens von ihr ausgegangen ist, er will ebenso von ihr entweichen, um selbst immer sonnenhafter zu werden. Das Recht hat die ewige Eigenbewegung des Planeten und ebenso die Bewegung um die herrschende Sonne. Als faktischer Zwang bewegt es sich um sich selbst, als Glied im System der sittlichen Begriffe dreht es sich um die freie Sonne. Wie im Inbegriff der Zahlenreihe jede Zahl sich gleichgültig gegen ihre Besonderheit verhält, damit aber diese doch nicht verneint, sondern nur uibersehen wird, so ist das Recht gleichgültig gegen die Besunderheit desjenigen, den es betrifft; es ist ebenfalls indifferent gegen die Gesinnung, mit der der Mensch sich zu ihm stellt; das Rechtsgebot befiehlt nicht den guten Willen, das Rechte zu tun; der böse Scheinheilige ist ihm nicht schlimmer als der pflichtbewusste Anerkenner des Rechtsgesetzes, der gute Verbrecher nicht besser als der bösegesinnte.

So fällt das eigentümlich Sittliche aaus ihm heraus, - oder es ist selbst das Sittliche, das seine Sittlichkeit verneint. Aber der Zwang ist auf das Äussere gerichtet, das Sittlichkeitsfeindliche der Sitte im Recht so aufgehoben; das Recht zwingt das Handeln, nicht die Herzen; durch das Recht wird der Mensch so zu seiner wahren Freiheit zurückgebracht. Das Recht kann nie wahrhaft unsittlich werden, und so ist es gerade auch das seine Unsittlichkeit verneinende Sittliche. Es steht auf dem Punkte, wo in der Ethik die höchste Gegensatzspannung erreicht ist; es ist einunddasselbe, nämlich das Recht, welches sowohl seine Sittlichkeit wie seine Unsittlichkeit verneint. Es ist die äussere Sittlichkeit als. wirkliche, und das Sittlich-Unsittliche des Inneren wird von ihm zu neuen Bildungen freigelassen.

Es ist somit durch den 2. Abschnitt der Ethik (das Gesetz) die allgemein-sittliche Sphäre zur 'Wirklichkeit gebracht; die Geltung-überhaupt ist selbst zur empirischen Tatsächlichkeit durchgedrungen (empirische Norm des Rechts). Aber dies Gesetz ist zum Zwang herabgesunken, der gleichwohl die Freiheit (Gesinnung), die Persönlichkeit freilässt; Freiheit (Gesinnung) und Zwang (Gesetz) stehen sich gegenüber - aber bereits ohne sich 
in ibrem Widerspruch zu stören. Das Gesetz ist selbst das aus Freiheit Geschaffene, und die wahre Freiheit ist jetzt die Freihcit des Gesetzgebens. Freiheit heisst jetzt die Selbsteinschränkung, d. h. das Sich-autonom-bestimmen. So kündigt sich die wahre Synthesis des Systems der Sittlichkeit an (3. Teil der Ethik). Wenn so die Einzelpersönlichkeit frei ist, sich selbst zu bestimmen, so steht ihr aus dem 2. Teil der Ethik nur das Gesetz-überhaupt gegenüber; dieses hat sie jetzt anfzunehmen und nach ihren einzelnen Wollungen zu verwirklichen. Es giebt sich jetzt die Einzelpersönlichkeit als einzelne, individuelle ihr eigenes Gesetz. Als allgemeine ist sie Rechtssubjekt, aber als einzelne, als die Individualität, die sich von anderen Iudividualitäten unterscheidet, war sie bis jetzt noch sittlich unbestimmt. Die Sittlichkeit war im Recht zur Wirklichkeit gelangt, aber diese Wirklichkeit war nicht mehr wahrhaft sittlich, sie verhielt sich indifferent gegen die Gesinnung, das Innere. Das Gesetz der Individualität aber ist die freie Verwirklichung der inneren Gesinnung durch die Vermittlung des Gesetzes: das Gesetz ist jetzt nicht die allgemeine Norm, das Gesetz der Gesetzmässigkeit (Kant), sondern es ist die inhaltsbestimmte Norm, das Individualgesetz. Der Einzelne giebt sich nach seiner Einzelheit das Gesetz -, so ist das Gesetz das unmittelbare Produkt der Freiheit, und diese ist nur noch im Gesetz. Alle Individualgesetze haben so die Gemeinsamkeit des Gesetzes, aber ihrem Inhalt nach unterscheiden sie sich. In der Gemeinsamkeit des Gesetzes ist im Individualgesetz der kategorische Imperativ gewahrt geblieben, er ist die Substanz, in der alle Persönlichkeiten als sittliche Individualitäten wurzeln und der sie ihre individuellen Inhalte als accidentelle Bestimmungen beigeben. Das allgemeine Gesetz hat gerade seine Wirklichkeit erst am Individualgesetz, dieses aber seine Gültigkeit nur am allgemeinen. „Handle nach deiner Bestimmung“ ist verwirklicht im jeweils individuellen Gesetz des individuellen Lebens, aber der Begriff dieses Gebotes ist doch nur das Allgemeine, das Gesetz der Gesetzmässigkeit des Wollens.

Aber insofern ist doch der Einzelpersönlichkeit die vollkommene Freiheit gelassen, sie nimmt den Inhalt ihres persönlichen Gesetzes aus sich selbst und ist in diesem Ergreifen des Inhalts frei von jeder beschränkenden Bestimmung. Das Individualgesetz ist daher noch nicht das wahre "Gesetz der Freiheit", - wohl ist es die Freiheit, welche das Gesetz giebt, aber ebenso 
steht diese Freiheit noch ausserhalb des Gesetzes; weil der freie Wille sein Sich-ein-Gesetz-geben gesetzlos vollzieht, nimmt er, was er vorfindet, und das Gesetz des Individuums wird so zur gesetzlosen Willkür.

So bleibt das Gesetz nur als die allgemeine Substanz übrig, in der das Sittliche überhaupt sein Leben hat; aber die individuelle Bestimmung ist ebensosehr Wollen aus Freiheit, und insofern sittlich, als Wollen ohne Gesetz, und insofern nicht sittlich. Die Einheit der Freiheit und des Gesetzes ist noch nicht zu einer ethischen Wirklichkeit gekommen; der ethische Individualismus ist daher notwendigerweise ebensosehr sittlich wie unsittlich.

Das Individuum ist daher die wahre Wirklichkeit der Freiheit, aber das (vorher im Recht zur wahren Wirklichkeit gelangte) Gesetz hat an ihm keine Wirklichkeit. Die Wirklichkeit des Individuums ist vielmehr die Freiheit der Gesetzlosigkeit; indem sie aber gesetzlos ist, ist sie nicht auf die Selbstbestimmung des Individuums gerichtet; dann wäre sie ja gesetzgebend und nicht gesetzlos; das Individuum richtet daher seinen Willen nach aussen, auf die Bestimmung anderer Individuen; das Ich wirkt jetzt nicht auf sich selbst, sondern auf das $\mathrm{Du}$. Die gesetzlose Freiheit der Individuen offenbart sich daher im Wesen der Gesellschaft; in ihr ist es nur das wirkende Ich, das Ich, das seine Wirkung ausser sich hat, die Ursache seiner Wirkung aber in sich. Die Gesellschaft ist dies gesetzlose Treiben der Individuen, in dem jeder Einzelne frei vom Gesetz ist; jeder ist seiner eigenen Willkür überlassen; so verneint sich in der Gesellschaft die Freiheit nach der Seite der Sittlichkeit. (Daher konmt es, dass in der Gesellschaft stets das Rechtsgesetz als das einzig übrige Moralische erscheint; aber nicht einmal dieses hat in ihr als dem gesetzlosen Treiben ein eigenes Dasein).

Aber in der gesetzlosen Verwirrung und in dem Wirken des Ich auf das $\mathrm{Du}$, ist das Ich wohl frei von sich selbst (als dem Gesetzgeber seiner selbst), nicht aber von dem Du als dem Ich, das es als sein $\mathrm{Du}$ zum Objekt der Betätigung hat. In der Gesellschaft ist so vielmehr niemand frei; jeder bestimmt, aber jeder wird auch bestimnt. Die Freiheit äussert sich so nicht im Gesetz, sondern in der Herrschaft.

Die unsittliche Freiheit and Willkür des Individuums wird in der Gesellschaft durch ebendieselbe unsittliche Freiheit und Willkür unterdrückt; in der Gesellschaft entsteht wieder das Ge- 
setz, aber als das der Herrschaft, welche Anordnungen giebt, somit nicht als Gebot der Autonomie, sondern der Heteronomie, d. h. für die Individuen als Zwang. Die Gesellschaft ist so der geregelte Zwang, aber als der nicht sittliche, als das Bestimmtwerden der Individuen ohne Rücksicht auf ihre Freiheit. Das An-und-für-sich der Gesellschaft ist so das Gesetz als das Vorsittliche, die rohe Macht der Herrschaft.

So stehen sich die Freiheit des Individuums (anf der alle wahrhafte Sittlichkeit berubt) und der Zwang des Herrschaftsgebotes gegenüber; aber es zeigt sich, dass sie sich gar nicht letzthin widersprechen; denn die Freiheit des Individuums geht nur auf das Selbst desselben und lässt das Verhältnis des Ich zum $\mathrm{Du}$ frei, das gesellschaftliche Gesetz der Herrschaft geht nur auf das Verhältnis des Ichs zum $\mathrm{Da}$ und lässt seinerseits das Ich als solches frei. Dieses hat also durchaus sittliche Wirklichkeit, wenn es das Gesetz der Herrschaft zum Gesetz seiner selbst macht, sich dem Zwang der Gesellschaft aus Freiheit unterwirft; das aber ist der Staat. Im Staat bestimmt nicht das Ich das Du und vice versa, sondern eben in der Rückwirkung parallelisieren sich die Wirkungen; jeder ist Ich und $\mathrm{Du}$ zugleich; darin kommt die blosse Herrschaft der einen über die anderen zum Schweigen, und die Gesellschaft sieht sich als wechselseitig gebundene Einheit, als wahre Gemeinschaft der Individuen scil. als Staat. Das Individuum ist so als freies wie als gezwungenes in der $\mathrm{Ge}$ meinschaft aller mit allen aufgegangen, und die Wirklichkeit des Sittlichen als des Gesetzes aus Freiheit heisst der Staat, wie er ebenso die sittliche Wirklichkeit der Freiheit als solcher als auch der Freiheit im Gesetze ist. Im Staat ist so der Gegensatz des Sollens und des Seins in seiner letzten Einheit enthalten. Das Gebot des Staates ist als empirischer Zwang, als Herrschaft, und das Sein des Staates ist in der Anerkennung des Staatszweckes, in dem politischen Bewusstsein der Bürger. D. h. das Sollen des Staates ist im politischen Sein wahrhaftes Sollen, und das Sein des Staates hat im politischen Sollen sein wahrhaftes Sein.

Aber die Staatsherrschaft ist wohl die Seite der Wirklichkeit des Gesetzes, und das Staatsgesetz ist wobl als das der Freiheit,. nämlich in dem politischen Gemeinschaftshewusstsein sanktioniert, aber darin ist doch die Herrschaft ein Zweifaches, erstens sie selbst, d. h. die Wirklichkeit und Macht des Gesetzes, zweitens der Gegenstand des politischen Sinnes; der Staat hat daher den 
Widerspruch in sich; seine Wirklichkeit ist eine doppelte; es ist wahr, dass die Sittlichkeit in ihm zur Wirklichkeit gekommen ist, aber es ist ebenso wahr, dass er noch eine andere Wirklichkeit hat, die im Dasein des Gesetzes als der blossen Herrschaft besteht.

Das Dasein des Gesetzes als der blossen Herrschaft fällt aber ausserhalb der sittlichen Sphäre überhaupt; es ist die soseiende Bestimmtheit des Gesetzes, die nicht in den politischen Sinn des Bürgertums aufgenommen werden kann. Die jeweilige Gestalt des Staates, seine besondere Art der Gesetzgebung und deren Inhalt hat keinen sittlichen Wert oder Unwert; der Staat ist so aussersittlich, anethisch. In dieser Doppelheit seiner Bedeutung, einerseits die absolute Sittlichkeit in deren vollentfalteter Wirklichkeit, andererseits die blosse (irrationale) Gestalt des Staates zu sein, liegt das wahrhafte Wesen des Staates. (Es ist deshalb aller Staatsphilosophie eigen, sieh um die Antinomie zwischen der historisch-sozialen und der ethisch-rechtlichen Seite des Staates zu bewegen, ohne in die Notwendigkeit dieses Widerspruches so einzudringen, dass begriffen wird, worin jene, worin diese zu setzen ist.)

Im Staate findet somit der Umschlag statt, durch den im gesamten System der Philosophie die grosse Cäsur entsteht: Das System der Sittlichkeit hatte in sich die Freiheit (für sich blosse Negation) zur faktischen Auswirkung gebracht; die Freiheit sah sich wirklicher und wirklicher werden, bis ihre Wirklichkeit sich verdoppelte und einerseits als Wirklichkeit der Freiheit, andererseits als blosse Wirklichkeit-überhaupt war. -

Die blosse Wirklichkeit aber ist das Anderssein des Geistes, der Freiheit; das Faktische ist nicht der Anfang der Philosophie, sondern lässt sich nur als Negation der Freiheit bestimmen (man sagt: das Besondere liese sich nicht aus dem Ich deduzieren, und indem man dies sagt, definiert man das Faktische negativ als das Nicht-rationale). Indem das Faktische als Gegensatz der Freiheit ist, ist es das Irrationale, diese das Rationale, oder beider Gegensatz ist der der blossen Wirklichkeit und der blossen Idee.

Die Wirklichkeit als solche ist irrational, unerkennbar, aber ihre Unerkennbarkeit ist selbst ihre Idee. Das Denken ist sich in Begriff der blossen Wirklichkeit doch wieder des Denkens bewusst: Die blosse Wirklichkeit ist so selbst nur Idee, die blosse Idee einer Wirklichkeit, als blosse Idee selbst ein Begriff ohne 
Wirklichkeit. Was die Wirklichkeit ist, ist also durch die Aussage ilhrer Irrationalität nicht begriffen, d. b. die Irratioualität ist auf dieser Stufe ${ }_{n}$ nur" Idee und besitzt für sich keine philosophische Wahrheit, sodass sie nicht als fester Ansgangspunkt und als Masstab der erkenntnistheoretischen Objektivitătsbegriffe dienen kann. Das Nur-Ideelle und das Nur-Reelle fallen so im Nur-Ideellen, als blosse Begriffe, zusammen. Dieses Nur-Ideelle ist aber das gänzlich Leere, Unbestimmte, der leere Begriff des Irrationalen. Dies leere Allgemeine, dass überhaupt irgend eins ist, ergiebt sich als das überall und nirgends lebende "Ist", der abstrakte Begriff der Einheit des Seins. Aber dieses Ist ist eben der blosse Begriff der Wirklichkeit, des Irrationalen; es hat den Bezug auf dieses in sich; die blosse Idee der Einheit ist so ebenso das Irrationale, das bloss-Wirkliche, das als "Ist" ist. Dieses Ist als die Wirklichkeit bedeutet ebenso das, was ist (wie es den blossen Begriff des Seins bedeutet). Das Ist als Sein bedeutet so den Inbegriff dessen, was ist; und dann ist dies das unbestimmt Viele, das zu dem Einen Inbegriff des Seins gebört, die blosse Mannigfaltigkeit. D. h. das Irrationale hat sich als quantitativ Irrationales bestimmt, als das Mannigfaltige.

Der Gegensatz der blossen Wirklichkeit und der blossen Idee hat sich zu dem der blossen Einheit „Ist" und der unbestimmten Vielheit dessen, was ist, herausgebildet. Jetzt finden sich die blosse Wirklichkeit und die blosse Idee als Abstraktionen in ihrer konkreten Einheit: die Idee bedeutet das Ist, d. h. die Wirklichkeit, und die Wirklichkeit bedeutet dạs Seiende, d. i. den Begriff dessen, was ist (Idee der Gegebenheit, des Dinges an sich); indem sie so ineinanderübergehen, entsteht ihre Einheit, d. i. das Wissen, die Erfabrung. Das Ist heisst dann der Verstand, auf welchem der Wert der Wirklichkeit, seine Gültigkeit beruht, das Mannigfaltige aber ist die Sinnlichkeit, auf welchem die Wirklichkeit dessen, was den Wert des Seins hat, fusst. Die Erfahrung ist so die Einheit, in der alles Mannigfaltige als Stoff zu einem Inbegriff möglichen Wissens zusammengehört. Die Einheit der Erfahrung ist die Totalität des Wissens als der zum Wissen gebrachten Mannigfaltigkeit. (Alle Erfahrung steht deshalb unter dem Zeichen des quantitativen Irrationalismus; das Mannigfaltige ist das negative, zu überwindende Moment der Erfahrung; diese Arbeit des Überwindens zeigt an, dass das Erfahrungswissen nicht den Begriff dessen vorstellt, das den Gegen- 
stand vou vornherein in sich hat; der Gegenstand ist vielmehr noch das Negative des Wissens, - der Begriff der Wirklichkeit geht daher jetzt von dem des Wissens zu dem des Gegenstandes über.)

Die Erfahrung ist das Wissen, dem Wahrheit, Erkenntnis des Ist, zusteht; der Inhalt des Wissens ist in der Erfahrung als ein ausserdem noch seiender zum Begriff gebracht; der Inhalt ist so noch der ausser dem Wissen stehende, der Gegenstand. Die Erfahrung ist so das Wissen vom Gegenstand, aber dieser liegt nicht in ihr, sondern verhält sich negativ zu ihr als $X$, problematischer Gegenstand. In der Erfahrung, kann man auch sagen, wird die Wirklichkeit als solche begriffen, und weiss sich das Begreifen als das Wissen, das die Wirklichkeit weiss. Begreifen und Wirklichkeit stehen aber so noch gegenüber, jenes ist das Subjektive, dieses das Objektive. Der Gegenstand liegt so noch ausserhalb des Wissens, und der Bezug, den dieses auf ihn hat, ist noch unbegriffen. Das Wissen hat so zwar bereits einen Inhalt, der aber nur aus Vorstellungen besteht, über deren Gegenstand in ihnen nichts enthalten ist. Sie stellen das nur-empirische Wissen, das A posteriori vor (Wahrnehmungen oder Vorstellungen nennt sie Kant). Der Satz der Immanenz wird am Erfahrungsbewusstsein als an ihm selbst gewonnen, und nicht an ihm als Bewusstsein des Gegenstandes; er zeigt deshalb das Nur-subjektive an der Erkenntnis an (auf ihm ruht der vorkantische Idealismus). Das A posteriori ist daher diejenige Beziehung des Wissens auf den Gegenstand, in der derselbe nicht ins Wissen gelangt. A posteriori heisst so, dass das Wissen den Gegenstand nicht erfassen kann, dieser also unbegriffen, irrational ist. Der Gegenstand als der ausser dem Wissen liegende, d. i. der an sich reelle (transscendente) ist so noch das Irrationale, das Unwissbare; (weil der Satz der Inmanenz in der Sphäre des subjektiven Idealismus ist, so verhält sich hier das Objektive, der Gegenstand als das Nicht-wissbare, das Nicht-immanente, d. h. als der Begriff des transscendental Reellen (blosse Wirklichkeit somit jetzt als Transscendent-Sein).)

Aber der Begriff des Irrationalen ist doch Begriff, selbst also als Irrationales rationalisiert (im philosophischen Bewusstsein). Als A priori ist das Aposteriori jetzt negativ bestimmt als das Nicht-apriori; d. h. das Apriori hat die logische Priorität vor dem Aposteriori. Indem so kein A posteriori ohne A priori sein kann, 
ist dieses nur für jenes. Im .Empirischen, d. h. im Verbältnis zum Gegenstand, lebt so der Begriff nur für den Nichtbegriff; der Begriff, das Apriori ist so für sich ohne Inhalt, ein Nichts, nur der Wert der Gegenständlichkeit-überhaupt.

So hat sich gezeigt, dass der Gegenstand ebenso das A posteriori (Irrationale, Rezeptive) wie das Apriori (Rationale, Spontane) vorstellt. Als A posteriori ist er aber noch nicht Erfahrung (nur Anschanung), als Apriori noch nicht Erfahrung, weil nur Denken. Der Gegenstand der Erfahrung hat daher die Doppeltheit an sich, weder im Aposteriori allein noch im A priori allein zur Erfahrbarkeit zu kommen. Indem aber das A priori nur in der Bestimmung für das A posteriori entstand, verneint es dieses nur, um es zu bejahen. Der Gegenstand der Erfahrung wird so das a priori gegenständliche A posteriori, d. i. empirisch-gegenständliche Wahrheit. Der Gegenstand ist danach weder rational noch irrational; dieses wird an ihm verneint, weil das Irrationale selbst Begriff ist, jenes, weil es nur für das Irrationale lebt. Der Gegenstand ist so für die Wabrheit gerettet, er ist das Nichtirrationale, die doppelte Negation des Irrationalen, die schlechthinige Überwindung seiner eigenen Irrationalität. Das Gegebene bleibt nicht chaotisch, es fügt sich dem Begriff, lässt sich begreifen; seine Begriffenheit aber ist nur die, dass es in die unendliche Sphäre desjenigen, das nicht-irrational ist, gesetzt, selbst nicht rational, also auch nicht deduzierbar ist (nicht Inhalt der Philosophie). Die Gegenständlichkeit hat so die Bedeutung der Erkennbarkeit, nicht Erkanntheit (Kant sagt: Affinität in der Deduktion der 1. A.). (Indem der Geist hier für seine Negation, das Irrationale, ist, ist das Empirische, die empirische Wirklichkeit der Abfall des Geistes von sich selbst; er ist in seinem Anderssein; dieses, das Nichtgedachte, ist die wahre Qualität der Wirklichkeit; das A posteriori oder Irrationale ist das Wirkliche der Wirklichkeit, das an ihr zu Bejahende; indem die Philosophie die Wirklichkeit als irrational anerkennt, geht sie über diese Irrationalität hinaus, indem sie sie begreift und die Notwendigkeit des Begriffes für sie deduziert; und eben nur auf die Weise, dass die Irrationalität im An und für sich aufgehoben wird, kann die Philosophie die ursprüngliche Irrationalität des Wirklichen begründen. Die Wirklichkeit bleibt so nicht im qualitativen Irrationalismus stehen. Der Kantianer bemerkt hier leicht bei Kant die doppelte Bedeutung seiner Begriffe: Verstand als das "Ich denke“ 
(quantitativ) und als Spontaneität (qualitativ), Sinnlichkeit als das Mannigfaltige (quantitativ), als Gegebenes (qualitativ). Besonders aber gebe ich anheim, zu bedenken, wie Kant für seine Kritik zwei Grundfragen formuliert, die, obwohl für den Verstand direkt entgegegengesetzt, für ihn doch die gleiche Bedeutung haben; das sind: wie ist Erfahrung, d. h. synthetische Urteile a posteriori möglich? und wie sind synthetische Urteile a priori möglich? Darin liegt das, was im vorhergehenden Abschnitt mittelst der dialektischen Methode ausgeführt und begriffen wurde).

Der Gegenstand ist der erfahrbare geworden, - aber nicht der erfahrene selbst. Das Wissen und sein Gegenstand sind so noch nicht eins geworden; nur das Wissen-überhaupt ist gegenständlich, und nur der Gegenstand-überhaupt ist gewusst. Die Bestimmung des Gegenstandes und seines Wissens in ihrer Einzelheit fehlt; der Gegenstand-überhaupt wird sich zu Gegenständen spezifizieren, indem er in die quantitative Mannigfaltigkeit des tatsächlichen Wissens eintritt. Das Wissen ist nämlich in sich bereits das sich Vervielfältigende, es hat das Mannigfaltige, wie sich gezeigt hat, in sich. Der Gegenstand aber ist das Allgemeine, das allen Vorstellungen unabhängig von ihrer Besonderheit Erkenntniswert verleiht; er ist so nur das beharrliche übersinnliche Substrat, der transscendentale Gegenstand, in dem die einzelnen Vorstellungen als Erkenntnisse wurzeln. Die Gegenständlichkeit ist so die Wertsubstanz des Erfahrungswissens, an der die bestimmten, besonderen Wissensinhalte als Accidenzen inhärieren, - und die Objekte des Wissens sind die einzelnen Gegenstände, Phänomena, blosse Vorstellungen, die in der Substanz des Gegenstandes, d. i. in ihrer Idealität ihre Objektivität besitzen. (Der Gegensatz der blossen Wirklichkeit und der blossen Idee, von dem wir' ausgingen, hat sich verändert; die blosse Idee wurde zum Begriff des blossen Wissens (1. Teil der Erkenntnistheorie), die blosse Wirklichkeit wurde zum Begriff des blossen Gegenstandes (2. Teil der Erkenntnistheorie); jetzt, wo wir den Übergang zum 3. Teil gemacht haben, zeigt sich umgekehrt, dass der blosse Gegenstand an der Wirklichkeit die blosse Idee vertritt (transscendentaler Gegenstand), - das blosse Wissen dagegen an ihr die blosse Wirklichkeit (Phänomenalität). So ist die Synthesis der beiden Teile vollzogen, und es ist kein Zufall, dass Kant, obwohl selbst ohne Einblick in den systematischen Zusammenhang, 
gerade diese Position des Denkens zur Fassung seines Prinzips gewăhlt hat: sein Lehrbegriff des transscendentalen Idealismus.)

Aber indem der Gegenstand nur das Allgemeine der Erkenntnis ist, ist jedes einzelne Objekt nach seiner Besonderheit nicht gegenstăndlieh, sondern nur subjektiv nach seiner jeweiligen Gewusstheit bestimmt. Das Besondere am Gegenstand ist daher nicht deduzierbar, ist empirisch-zufällig, wie Kant sich ausdrückt; da es nicht gegenständlich ist, ist es nur im Wissen, d. h. das Wissen bestimmt in seiner jeweiligen Besonderheit das Besondere am Gegenstande. Erst wenn die Besonderheit des Besonderen aufgehoben, d. h. erst wenn das Besondere durch das Ganze bestimmt wäre, d. h. wiederum erst in der Totalität des Wissens würde dessen besonderer Inhalt notwendigerweise mit dem Besouderen am Gegenstande übereinstimmen; aber da das Wissen die Besonderheit am Gegenstande bestimmt, so hat dieser dieselbe nicht in sich, sondern ausser sich. Es ist dem Wissen deshalb nur A ufgabe, das Besondere am Gegenstande zu bestimmen, d. h. es kann diese Bestimmung nie vollkommen ausführen; sonst wäre es ihm nicht Aufgabe. Die Gegenstände sind also an und für sich quantitativ irrational, in ihrer Totalität nie wissbar, ihre Besonderheiten immer durch andere Besonderheiten bestimmt. Sie sind das Bedingte, das in sich selbst seine Bedingungen sucht und nicht findet; die Erscheinungswelt kommt so in sich nie zu Ende; sie ist verurteilt, den unendlichen Progressus zu gehen.

Den unendlichen Progressus auszuführen, ist die Aufgabe des Wissens; indem es diese Aufgabe anerkennt, macht es sie zu seiner Voraussetzung (regulatives Prinzip in der Terminologie Kants); für es ist die Unendlichkeit beides zugleich, Ziel wie Grundlage. Aber indem die Unendlichkeit Fundament ist, befindet sich das Wissen doch stets am Ende: das unendliche Fortschreiten ist als unendlich eben unendlich, d. h. es giebt nichts jenseits von ihm, es ist so stets am Ende; der unendliche Progressus hat so die zwei Seiten (die beiden Seiten der Kantischen Antinomien), nie und immer am Ende zu sein. In der Totalität fallen der Gegenstand und sein Begriff auch nach der. Seite der Besonderheit zusammen. Indem das Wissen seine Totalität zur Grundlage seiner selbst erhebt, d. h. indem es (empirische) Wissenschaft wird, erhebt es sich zur Identität mit dem Gegenstand, - - und setzt zugleich die Erreichung dieser Identität in das nur asymptotisch erreichbare Ende der Zeit-überhaupt. 
Das Besondere ist so aus seiner Vereinzelheit in das System, die Gemeinschaft mit allen anderen Besonderheiten hinübergeleitet worden. Die Wissenschaften geben so das Wissen um die Wirklichkeit (als Welt). Die Wissenschaft nämlich ordnet alles in Systeme ein, sodass die Gegenstände ihre Irrationalität verlieren; in dem Begriff der Wissenschaft gilt das induziert Besondere auch als deduziert; die Wissenschaft hat daher das unbedingte Zutrauen zu sich selbst: was heute noch nicht ist, wird morgen werden; und dieses Zutrauen ist ihr Recht, sagt die Philosophie.

Der Gegenstand war vom rein Irrationalen zum rein Rationalen (in der Sprache Kants vom Ding an sich als Affizierenden zum Ding an sich als Idee) fortgeschritten, und so war das Wissen, das zuerst auf Seiten der Idee stand, gerade als tatsächliches Wissen erst $\mathrm{zu}$ seiner Idee, der seiner Übereinstimmung mit dem Gegenstande, gekommen, - umgekehrt der Gegenstand, welcher zuerst als blosse Wirklichkeit auftrat, als Idee des transscendentalen Gegenstandes erst zu seiner erfüllten Wirklichkeit, d. i. zum Kosmos.

Der Kosmos ist das Objekt der Wissenschaften; aber diese sind abhängig von dem tatsächlichen Stande des Wissens, d. $h$. der Kosmos kommt nicht in dem Begriff der Wissenschaft zu Stande, sondern diese muss es zeigen, dass ihre Erkenntnisse zur Welterkenntnis zureichen; es ist also nur eine Möglichkeit, dass sie dahin gelangen können. Die Welt fällt so ihrèr Wirklichkeit nach wieder ausserhalb des Wissens, die Wirklichkeit der Welt kommt nicht zu ihrem Dasein, sondern bleibt Idee. (Das Ideelle pocht wohl an der Tür der Natur, aber der ihr öffnen könnte, steht selbst draussen - der Geist.) Die Wissenschaft ist die Verwirklichung der Weltidee nur in potentia, weil sie selbst (die Wissenschaft) nur die blosse Möglichkeit bedeutet, zum Ziel der Erkenntnis zu kommen. Das empirische Wissen scheidet sich so von der Welt; diese als unmittelbar reale ist nur Idee, ein die Erfahrungsmöglichkeit überfliegender Begriff eines Gegenstandes. Gleichwohl bleibt das Wissen von der Welt eine Idee, welche $\mathrm{zu}$ verwirklichen ist; und dieses Ideal der Wissenschaft (wie der einzelnen Wissenschaften) ist selbst doch in jedem Einzelzustand der Wissenschaften als in irgend einer Weise verwirklicht anzusehen. Genauer: mit der Vervollkommnung des Wissens wächst dessen Wert, - und der Fortschritt des Wissens erledigt Ziele, wie er neue schafft; neue Voraussetzungen, neue 
Ziele! Das Ziel der Wissenschàft, ihr Ideal wurzelt so selbst in dem jeweiligen, wirklichen Zustand der Wissenschaft; die Idee der Wissenschaft von der Welt zeigt sich so nicht nur als blosse Idee, sonderu auch als dasjenige, das sich verwirklicht. Hierdurch scheint die Idee aus ihrer Apriorität in die Zufălligkeit hinuntergezogen zu werden; aber in Wahrheit basiert letzthin wieder der jeweilige Zustand der Wissenschaft auf der Idee von ihrem idealen Endzustand, indem er eine wirkliche Vorstafe zu der Verwirklichung des Idealbegriffes der Wissenschaft ist. Die Geschichte der Wissenschaft ist so das wahrhafte Dasein ihrer Idee, und der individuelle Zustand der Wissenschaften zu irgend einer Zeit hat die Bedeutung derjenigen Wirklichkeit, welche der Idee des empirischen Wissens zukommt. Die Idee der Welt hat so ihre Wirklichkeit in der Geschichte der empirischen Wissenschaften; wenn diese Geschichte ihrem Begriff entsprechend nie zum Ziele gelangt, so verurteilt sie ebenso die Weltidee zur Unwirklichkeit. Diese (die Weltidee) hat also ebenso ein Dasein wie sie es nicht hat. Die Idee des Kosmos verlangt zuviel, als dass sie ihre Verwirklichung in der tatsächlichen Entwicklung der empirischen Wissenschaften finden könnte; sie könnte es, wäre sie nur Geschichte. (Als Naturidee erfordert die Welt ihre Realisation zu jeder Zeit und begnügt sich nicht mit dem allmählich anwachsenden Dasein ihrer Wirklichkeit, wie es die Geschichte ihrer Idee nach tut.)

Der Gegensatz der blossen Wirklichkeit und der blossen Idee hat seine höhere Stufe erreicht; er ist zu dem Gegensatz der Natur und Geschichte geworden. In der Natur ist auch die Idee, aber nicht als faktische, sondern sie steht nur allgemein im Hintergrunde (als übersinnliches Substrat der Kausalität aus Freiheit, sagt Kant; als absoluter Wert, sagen die Modernen). In der Geschichte dagegen wird die Idee selbst zur Tatsache, der Wert zum Faktischen (man spricht deshalb von empirischen Werten und nennt ihren Inbegriff Kultur). Dies kommt so zustande, dass die Idee der Geschichte sich als das zeigte; deren Wirklichkeit mit ihrem Begriff zusammenfällt; sie bedeutet das sich Entwickelnde-überhaupt. Für die Welt war der Zweck noch dos Ziel der Wissenschaften, das als Aufgabe nur für das Subjekt galt; für die Geschichte ist.er (der Zweck) die objektive Aufgabe selbst; der gegenständliche Begriff: Geschichte hat den Sinn des objektiven Zweckes. Der Zweckbegriff konstituiert so den all- 
gemeinen Begriff von der Geschichte. Der Zweck der Geschichte hat so unmittelbar sein Dasein an dem historischen Werdegange selbst, der zu ihm, dem Zwecke führt: alles, was in der Geschichte wirklich wird, ist ein Beitrag zur Realisation des Menschheitszweckes; die Idee ist so selbst in dem Einzelnen, dem Individuell-faktischen lebendig. Diese Faktizitäten der Geschichte, ihre einzelnen Tatsachen und Kulturwerte, sind als Teile der zu realisierenden Idee auch nach der Seite ihrer Individualität begriffen, besitzen also Notwendigkeitscharakter. Aber andererseits schreibt der allgemeine Zweck den einzelnen Tatsachen nicht ihre Besonderheit vor, sodass sie irrational sind und nicht aus der allgemeinen Geschichtsidee als notwendig begriffen werden können, nur Zufälligkeitswert haben. - (So haben sich die Gegensätze gekreuzt: die Idee ist nicht zur Wirklichkeit-überhaupt, sondern zur tatsächlichen Wirklichkeit gekommen (Geschichte), während die Wirklichkeit nicht nur bei ihrer Idee, sondern bei der blossen Idee endete (Welt); die Idee, der Wert ist so empirisch, die Wirklichkeit aber problematisch geworden.)

Damit ist angezeigt, dass die Idee als empirische zur Allgemeingültigkeit, die Wirklichkeit als problematische zur Faktizität zurückkehren wird. Diesen Fortschritt macht aber die Kunst. Diese ist das Überhistorische, in dem alles. Einzelne nicht als Bestandteil der Entwicklung, sondern wie ein ewig Wiederkehrendes, wie Natur, zu bewerten ist. Die Kunst überwindet die Zeit, indem sie zeitlos ist; als einzelnes, nicht erst als Teil des Ganzen ist sie ewig. Indem sie aber selbst ein Historisches ist, überlistet sie mehr die Geschichte, als dass sie sie überwindet. Das Wirkliche, Faktische selbst bat in ihr als Ausdruck der Idee Notwendigkeitscharakter bekommen, aber eben nur als Faktisches; d. h. die Idee der Kunst kann sich nur in dem einzelnen Werke ausdrücken. Idee und wirkliches Dasein fallen so zusammen; die Wirklichkeit ist als Kunst selbst Idee geworden, und die Idee hat in der Kunst ihr unmittelbares Dasein im jeweilig Faktischen; es giebt also keine Idee der Kunst ausserhalb ihrer Wirklichkeit. Die Zufälligkeit der historischen Tatsache ist in der Wirklichkeit der Kunst abgetan. In der Kunst erscheinen die Momente: Wirklichkeit und Idee so wieder in ihrer ursprünglichen Reinheit: dem Sein nach ist in der Kunst nichts, dem Wert nach alles allgemein. Aber diese Momente stellen in der Kunst keinen Widerspruch mehr dar, und so kündet sich in der Kunst ein Höheres, Gott, 
an. Aber dies ist nur ein Ankünden, - denn nur in ihrer Faktizităt hat die Kunst jene Momente aufgehoben; nur insoweit sie tatsächliches Einzeldasein hat, ist in ihr das Sein als besonderes, die Idee als allgemeine vorhanden. Nichts, was tatsãchliche Wirklichkeit hat, ist daher von der Kunst ausgeschlossen, sondern nur das Sittliche und das Absolute; die Kunst gehört daher selbst noch zum 2. Teil der Philosophie, dem System der Wirklichkeit; sie ist sogar dessen wahre Synthesis und Vollendung, indem allein die Kunst eine notwendige Wirklichkeit repräsentiert, d. h. eine solche, an der nicht noch die Unvollendbarkeit der Welt und die Zufälligkeit der Historie hängt. Die Kunst allein ist diejenige Wirklichkeit, der Notwendigkeit zusteht.

Indem so die Kunst dasjenige ist, in der die Idee im Soseienden, Faktischen ihren Ausdruck erstrebt, hat sie die Eigentümlichkeit, dass ihre Idee ebenso individuell ist als ihr Sein. Wäre die Idee der Kunst allgemeiner als ihre Wirklichkeit, so wäre diese nicht notwendiger Ausdruck der Idee; es könnte auch eine andere Wirklichkeit die Idee ausdrücken. Für Kunstwerke kann es keine Gattungsbegriffe geben, ohne dass die Kunst zur Nachahmung herabsänke. Die Wirklichkeit als Kunst besässe nicht Notwendigkeit, wenn die Idee in der Kunst nicht stets originell wäre; nur durch die Originalität besitzt die Kunst eindentig bestimmte Wirklichkeit. Die Originalität ist so der Ausdruck dafür, dass das individuelle Sosein nur als Ausdruck einer individuellen Kunstidee Notwendigkeitswert besitzt. Die Einzigkeit der künstlerischen Idee und die ihres Wirklichkeitssubstrates sind so aneinander gebunden; die Idee des Kunstwerkes kann nicht das Wirklichkeitssubstrat wechseln, ohne die ästhetische Notwendigkeit zu verlieren, und das Wirklichkeitssubstrat kann nicht die Kunstidee vertauschen, ohne dass das Faktische in den Werken die Notwendigkeit verlöre. Diese, die Einzigkeit der Wirklichkeit in der Kunst, geht so in die Einzigkeit der Kunstidee über, - - die Kunst ist stets originell. In der Gemeinsamkeit der Wertsphäre (Kunst) hat so doch jedes einzelne Werk seine einzigartige Bestimmung, welche erst seine Originalität ausmacht. Das Originelle ist so die accidentelle Prädizierung des Kunstwerkes.

Aber die Zugehörigkeit zur Kunst liegt dann nicht in der Originalität, sondern in der allgemeinen Kunstsubstanz. Die Originalität bringt dann das Kunstwerk nicht mehr in Gefahr, seine 
spezifische Wertsphäre zu verlieren, aber sie büsst selbst den ihr eigentümlichen Wert der Notwendigkeit ein; die Originalität konstituiert dann nicht mehr das Kunstwerk als Kunst, sondern ist die gleichgültige Inhaltsbestimmung geworden, die so und anders sein kann. Die Originalität muss so selbst den Wert der Kunstsubstanz erhalten, die Besonderheit des Kunstwerkes muss durch den allgemeinen Kunstwert erzeugt werden, nicht nur ihm accidentell sein. In diesem Hervorbringen ist die Kunst nur als Kunst, also frei von anderen Beeinflussungen; dieses Sichselbsterzeugen der Kunst heisst ihre Genialität. Die Kunst-überhaupt erhält so die Bedeutung, gerade das Originelle am Kunstwerk hervorzubringen. In diesem Schaffen besteht die absolute Freiheit des Produzierens, die Genie ist. Das Kunstwerk als originelles und künstlerisch-wertvolles ist so das Produkt des Genies als einer freien Kraft, und indem diese erst die Seite der Originalität hervorbringt, so steht sie selbst als der allgemeine Grund, d. h. ihre Regel über dieser. Die Freiheit des Schaffens begründet hier die Notwendigkeit des Geschaffenen, d. h. das Genie ist ein Vermögen, das als Natur der Kunst die Regel giebt. Das Genie schafft zwar werterzeugend, also allgemeingültig, aber auch originell, also nicht allgemein. (Die Kunst ist so exemplarisch, ohne bestimmte Kunstgesetze zu geben; sie untersteht der Regel, aber diese Regel ist nur transscendental-, nicht formalallgemein. Die Genialität bringt so die Seite der Idee im Werke zur Wirklichkeit, aber eben diese faktische Realität hat den Wert, exemplarisch zu sein, $d$. $h$. sie ist allgemein. Die früheren Momente der soseienden Wirklichkeit und der allgemeinen Idee finden sich so wieder in der Originalität und der Genialität; aber wenn Originalität das Faktische des Werkes, Genialität seine Allgemeinheit bezeichnet, so ist doch die Originalität des Faktischen nur durch die Genialität und diese nur durch jene. Es wird sich also ergeben, dass Originalität und Genialität nur Abstraktionen bedeuten, die sich in ihrer höheren, wahrhaften Einheit zu finden haben.)

Der Begriff hat in sich den des kunstproduzierenden Genies erzeugt; dieses nennen wir den Künstler, das Subjekt der Kunst. Ihm tritt das Erzengte als das Werk, das Objekt der Kunst gegenüber. Die Originalität bestimmt sich so als Wert des Werkes, die Genialität als die des Künstlers. Jene wird für den Künstler zur Norm, die Genialität für das Werk zur Ursache. Das vom genialen Künstler erzeugte Werk ist so aber selbst ein 
geniales Werk, und dieser Begriff tritt so dem Künstler ebenso als Norm gegenüber (wie vorber bereits die Genialităt); und die dem Künstler anbefohlene Originalität tritt im originellen Werk für das Werk ebenso als Ursache auf (wie vorher die Genialităt). Das Werk hat so die Ursache seines Kunstwertes ebenso in seiner eigenen Originalität wie in der Genialität des schaffenden Künstlers, und der Künstler bat die Norm für sein Schaffen ebensogut in seiner eigenen Genialität wie in der Originalität des zu schaffenden Werkes. Es zeigt sich so, dass das Objekt der Kunst, wenn es vom Künstler hervorgebracht wird, ebenso sich selbst hervorbringt, und das Subjekt der Kunst in seinem Schaffen ebenso sich selbst folgt als dem zu schaffenden Werke. Subjekt und Objekt bewirken sich so wechselseitig: das Subjekt erzeugt das Werk, aber das Werk entzündet in ihm den Künstler, welcher, insofern das Werk ihn entzündet, nicht mehr der Produzierende, sondern der Betrachter ist; und dieser verhält sich als wahres Kunstsubjekt, wenn sein Betrachten zum Beurteilen wird und so aus dem Verke den Kunstwert herauslöst. Das Subjekt ist so ebenso Künstler wie Betrachter, - das Objekt ebenso Kunstwerk wie Kunstwert. Aber damit sind Subjekt und Objekt der Kunst erst zu ihrer Selbständigkeit gelangt; indem sie sich wechselseitig hervorbringen, hat keiner das Übergewicht über das andere. Die spezielle Subjektivität des Künstlers ist so im Werke ausgeschaltet, d. h. das Werk hat keinen bestimmten Zweck, obwohl es in seiner ästhetischen Produzierbarkeit durch das Subjekt doch allgemein zweckmässig bestimmt ist (Kants Zweckmässigkeit ohne Zweck). Ebenso verschwindet die Besonderheit des Werkes für das beurteilende Subjekt, es hat kein bestimmtes Interesse für dasselbe; aber da es für dasselbe doch ästhetisch erweckend wirkt, so hat es für es doch den Wert des Gefallens (Kants Wohlgefallen ohne Interesse). (Künstler haben gerne ausgesprochen, dass sie, wenn sie schaffen, doch nur selbst empfangen; Goethe weiss, dass er "nicht sich selbst gemacht" habe. Im Empfangen wird andererseits der Künstler auch geschaffen; die ästhetische Lebensanschauung nivelliert daher den Unterschied zwischen Produzierendem und Geniessendem; hierin liegt das Wahre, wie wir sahen, dass das Genie nur als allgemeines Subjekt produziert; der schaffende Künstler fühlt so in seinen Intuitionen die Besonderbeit seiner selbst ausgeschaltet, fühlt sich über sie in das rein ideelle Sein erhoben; aber deshalb bleibt er doch 
der Einzelne, dem Sein nach, und der Ästhet wird nie wahrhaft zum Künstler. Hier sehen wir so einen zunächst unlösbaren Widerspruch sich erheben, den zwischen dem Künstler und dem Kunstbetrachter - oder was dasselbe ist, zwischen dem Werke und dem Werte der Kunst. Der Kenner der Kritik der Urteilskraft wird bemerken, dass es eben dieser Gegensatz ist, der die unsystematische Gliederung des Buches bedingt; denn Kant geht in ihm allmählich, aber unvermittelt von dem Begriff des Betrachtens (des. Wertes) zu dem des Künstlers. (des Werkes) über. - Indem diese beiden Begriffe nicht durch das Bisherige entwickelt sind, liegt in ihnen die Anfgabe der jetzt folgenden Teile der Ästhetik.)

In der Gemeinschaft zwischen Subjekt und Objekt der Kunst ist die Wirklichkeit der Kunst ebenso ins Subjekt wie ins Objekt gelegt; die Kunst ist im ästhetischen Betrachten ebenso wirklich wie im Werke und ist so in die Gemeinschaftsbeziehung von Subjekt und Objekt gesetzt. Damit ist aber die Wirklichkeit der Kunst problematisch gemacht, sowohl das blosse Kunstsubjekt wie das blosse Kunstobjekt sind verschwunden. Was als wirklich übrig bleibt, ist die Beziehung zwischen beiden, das ästhetische Schaffen und Geniessen. Aber im Schaffen und Geniessen hebt sich die Gemeinsamkeit zwischen Kunstsubjekt und -objekt auch zugleich wieder auf, indem das Subjekt das Werk sich gegenüberstellt als das, was ausser ihm ist. Das Subjekt hat so sein Tun aus sich heraus gesetzt, ihm eine eigene Wirklichkeit gegeben. In der Wirklichkeit der Kunst ist mithin das Subjekt verneint, das Kunstwerk hat die Selbständigkeit des Wirklichen gewonnen. Diese Selbständigkeit seiner als eines Kunstwerkes ist die ästhetische Form als die Einheit, in der das Werk sein Für-sich-sein besitzt. Das Werk hat sich so unabhängig vom Subjekt des Künstlers wie des Betrachters gemacht, es führt sein eigenes Dasein und dürstet nicht danach, angeschaut $z \mathfrak{u}$ werden. Durch die ästhetische Form ist dem Werk diejenige Wirklichkeit gegeben, die ihn rom Kunstsubjekt befreit und eine eigene „ästhetische Wirklichkeit" begründet.

Aber die ästhetische Wirklichkeit des Werkes ist nur die Selbständigkeit an sich; sie ist allen Werken in gleicher Weise eigen, ist nur die leere Einheit des Kunstwerkes-überhaupt, dessen abstrakter Begriff. Um über seinen blossen Begriff hinauszukommen, um individuell-wirklich zu werden, muss das Werk in 
die Mannigfaltigkeit des Soseienden hineintauchen; in dieser Vielheit der blossen Wirklichkeit gewinnt das Kunstwerk seine soseiende Realität; es unterscheiden sich jetzt die Werke untereinander. Ein jedes hat seine eigene Vielheit, d. h. seinen eigenen Inhalt. Der Inhalt der Kunstwerke ist das sie spezifizierende Moment, im Inhalt kommt so das Kunstwerk zu seiner Faktizitāt.

Aber in seinem Inhalt geht es zu Grunde; denn der Inhalt ist die unübersehbare Mannigfaltigkeit, in ihr kommt das Kunstwerk nicht zu seiner Eiuheit und Selbständigkeit; im rein Mannigfaltigen ist jedes Aufhören ein blosser Zufall; das Kunstwerk verliert seinen Rahmen und so seine Zugehörigkeit zu einer ästhetischen Wirklichkeit, es geht ins Anästhetische über. Wenn das Kunstwerk so ein Dieses ist (ein Stück Natur, eine Erzählung, ein Gefühl, ein Stück Kultur), so wird dies Dieses doch in seiner Beziehung auf den Begriff des Kunstwerkes aus der Mannigfaltigkeit des bloss Wirklichen, aus der Fülle des bloss Natürlichen oder Historischen, herausgehoben; wieviel und was den Inhalt ausmacht, ist zwar zufällig; aber indem die Kunst einen Inhalt erhält, ist dieser aus dem ausserästhetisch Wirklichen herausgehoben, hat so seine Grenze und Einheit als ein für sich Ganzes erhalten. Im Inhalt kehrt so das Kunstwerk zur Einheit der Form zurück, - der Inhalt ist jetzt das Geformte und die Form das Inhaltserfüllte, der Inhalt als Ganzes zu seiner Einzigkeit gekommen; das Kunstwerk ist jetzt als totale Individualität sowohl eine Tatsache wie eine ästhetische Wirklichkeit. (Es macht der ästhetische Realismus den.Inhalt, der ästhetische Idealismus die Form zu seinem Prinzip; wenn dagegen eingewendet wird, dass die Wahrheit wohl in der Mitte läge, so ist das richtig; aber es muss genauer ansgesprochen werden, worin in dem mittleren Ausgleich die einzelnen Rollen beider beständen. Es muss gezeigt werden, wie jeder bestimmte Formbegriff, wie etwa Komposition, zentrale Anordnung, straffe Durchführung der Handlung u. s. w., selbst schon wieder Inhalt bedeutet, und wie es so eine ganze Anzahl von Forminhaltsbegriffen geben kann, in denen die Betonung auf Seiten der Form, die Unterscheidung aber anf Seiten des Inhalts steht; und ebenso würden von Seiten des Inhalts Ausdrücke, wie Stimmung, monumentale Behandlung, Erregtheit gebraucht werden, die aber bereits eine einheitlich geformte Heraushebung von Wirklichkeitssubstraten bedeuten; und solche Inhaltsformbegriffe hätten dann die Betonung auf Seiten des Inhalts, 
die Unterscheidung aber auf Seiten der Formung. In Wahrheit sind beides „Momente“ im Begriff des guten Kunstwerkes.)

Das Werk ist nur dadurch zur ästhetischen Wirklichkeit geworden, dass es sich durch die ästhetische Form von dem gewöhnlich Wirklichen unterscheidet; als ästhetische Wirklichkeit, d. h. als ästhetisch Wertvolles oder -widriges hat es den allgemeinen Bezug auf ein bewertendes Subjekt bekommen, und tritt so wieder in die Gemeinschaft von Kunstsubjekt und -objekt ein. Das Subjekt hat jetzt die Entscheidung zu treffen, ob das Werk zu seiner ästhetischen Welt gehört; es hat jetzt den Wert des Kunstwerkes zu beurteilen. Das Kunstwerk kann so nicht mehr für ausserästhetisch erklärt werden, vielmehr ist es entweder ästhetisch wertvoll oder wertwidrig. Wenn es so als geformter Inhalt nach der Seite seines Kunstwertes beurteilt werden soll, so bezieht sich die Fragestellung nicht auf den Wert seines Inhalts, sondern auf den seiner Form als Bewältigerin des Inhalts; es fragt sich, ob aller Inhalt in der Tat geformt worden ist oder ob etwa ungestaltete Inhaltsreste zurückgeblieben sind; ist ersteres der Fall, so ist der Inhalt (der durch Begriffe ausdrückbar ist) durch die Form in Anschauung gewandelt; alles ist dann nämlich für den ästhetischen Beurteiler nur in ästhetischer Hinsicht gegeben. Anschauung und Verstand finden sich dann in Übereinstimmung; das Werk befriedigt den Geschmack, hat den Wert der Schönheit; anderenfalls würde es hässlich, geschmackswidrig sein.

In der Schönheit aber, die nur auf dem ästhetischen Wertüberhaupt beruht, ist der Inhalt wieder ausgelöscht, das Wirkliche ist abgetan (die Formalästhetik steht deshalb auf dem reinen Geschmacksstandpunkt); die Schönheit ist dann nichts als Nichtdasein von Disharmonien, als Verneinung des. Hässlichen. Die Schönheit für sich ist so allen Werken in gleicher Weise eigen; schön sind sie und befriedigen den Geschmack, haben ihre Individualität aber verloren. Die schönen Werke sind so zum Begriff des Schönen zusammengeschrumpft. Das Schöne müsste so den Hungertod sterben, wenn es nicht aus einem Jenseits von schön und hässlich Nahrung bekäme. Dieses Jenseits aber ist der Inhalt, als ungestalteter genommen; es ist der Inhalt als besonderer, an dem die Schönheit zur Wirklichkeit des Kunstwerkes zurückkehrt; aber eben darin ist das weder Schöne noch Hässliche, der Inhalt als ungestalteter, auch als dasjenige gesetzt, das den spezifischen Wert der einzelnen Werke begründet. Der unge 
staltete Inbalt ist so selbst ein ästhetischer Wert; der Inbalt dringt als Inlialt in die "ăsthetische Wirklichkeit" ein; als solcher ist er das, was als Inbalt nicht in die Einheit der Form gebracht werden kann; er ist ein Zuviel für die Form, ein im ästhetischen Sinne schlechthin Grosses, Kants Begriff des Erhabenen; alles andere (d. h. alles formal gestaltbare) muss im Verhältnis zu ihm für klein gehalten werden.

Jedoch das Erhabene besteht so nur ganz allgemein darin, dass etwas am Kunstwerk nicht mehr anschaubar ist, weil es za gross für die Anschaung ist, d. b. nicht geformter Inhalt ist. Das Erhabene gehört so zu einer ästhetischen Wirklichkeit, welche für das Subjekt nicht mehr auffassbar ist; der individuelle Inhalt des Werkes kommt so gar nicht in das Werturteil hinein; das Subjekt, das ein Erhabenheitsurteil ausspricht, bewertet daher in ihm nicht das Werk, sondern sein subjektives Verhältnis zum Werk; es beurteilt ästhetisch die Unmöglichkeit, das Werk ästhetisch beurteilen zu können. Wenn also das, was am Werk bewertet wird, die Unmöglichkeit, es zu bewerten, ist, so wird es ebendarin doch bewertet. Auch der ungestaltbare Inhalt tritt so in das ästhetische Verhältnis zum Subjekt ein, ist entweder wertvoll oder wertwidrig. Damit ist er auch eine ästhetische Wirklichkeit geworden und als solche für das Subjekt sogar anschaubar. Wenn so die Ungestaltbarkeit des Inhalts selbst geformt wird, erweist sie sich als seine Fähigkeit, in seiner Inhaltlichkeit selbst ästhetisch wertvoll zu werden. Seine Ungestaltbarkeit ist dann nicht für das ästhetische, sondern nur für dasjenige Subjekt geblieben, das ihn nicht ästhetisch, sondern als blossen Inhalt fassen will, d. i. für den Verstand. Der Inhalt ist so ein verstandesmässig Unbegreifbares geworden, seine Anschauung ist zu gross für den Begriff geworden (Kants ästhetische Idee). Schönheit und Erhabenheit finden sich überall, wo Gegenstände von Betrachtern allgemein ästhetisch bewertet werden; die ästhetische Idee aber (welche Schönheit wie Erhabenheit in sich schliesst) als das unbestimmbare Bestimmte, das jedem Werke zu Grunde liegt, geht auf denjenigen zurück, der ihm diese Bestimmtheit gegeben hat, d. i. auf den Künstler. Die ästhetische Idee ist sc die Idee, nach der als Regel das Genie sein Werk hervorbringt; Genialität ist daher das Vermögen ästhetischer Ideen (Kant).

Die ästhetische Idee ist so die absolute Verneinung des bloss Schönen, dem sie nicht widerstreitet, sondern es als die allgemeine 
ästhetische Wertrealität aller Kunst zu Grunde liegen lässt. Die ästhetische Idee selbst erzeugt über die Schönheit hinaus noch den künstlerischen Wert des einzelnen Kunstwerkes nach seiner Einzelheit. Aber sie bringt es nicht fertig, dass die Wirklichkeit, welche sie in der Anschauung hat, restlos ausgedrückt werden kann, in Wort und Begriff; auch für die ästhetische Wirklichkeit bleibt so die Wirklichkeit noch das Überlegene. Sie bedeutet zwar den schaffenden, also freien Geist, den intellectus intuitivus, der die Unendlichkeit des Unbegrenzten (Absoluten) in sich hat, und ist insofern frei von allem Faktisch-endlichen, - aber nur darin, dass derselbe in seiner Faktizität (in seiner Angeschautheit) unbegreiflich ist, ist er unbegrenzt. Indem der schaffende Geist noch das Unendliche in endlicher Bildung erzeugt, bringt er noch nicht sich selbst hervor, sondern ist noch an das Tatsäcbliche, das es schafft, gebunden. Die Kunst hat diese ihre eigene Faktizität gegen ihre Absolutheit und ist nur im Verhältnis zu der Endlichkeit ihres Kleides ein Unendliches. Sie ist so das Absolute und ist es nicht - es ist der „unbekannte Gott“, der in der Kunst lebt; das Unendliche, das die Kunst als höchste Stufe des Endlichen aus sich heraustreibt, ist an sich selbst das Absolute. (Einerseits ist jedes einzelne Kunstwerk Darstellung der Idee der Kunst, andererseits ist jedes Werk originell, und so giebt es die vielen Kunstwerke, die etwas anderes sind als die blosse Idee der Kunst. Diese Vielheit benötigt die Zeit, um sich in ihr darzustellen. Die Kunst hat daher zwar eine Geschichte, aber diese Geschichte hat keinen Begriff, dem sie als idealen Ziele zusteuern könnte, - eben weil nicht erst alle Werke vereint, sondern bereits jedes Werk der Kunstidee Wirklichkeit giebt. Die Kunstgeschichte ist keine einheitliche Entwicklung and ohne den Masstab einer solchen, in der das Höhere auf das Niedere folgen würde (wie in der Weltgeschichte), sondern es ist gänzlich irrational-zufällig, wann das Höhere, wann das Niedere in der Kunst zu Tage tritt. - Die Kantianer mögen hier daran denken, dass das übersinnliche Substrat des Ästhetischen bei Kant nur in der Dialektik der Urteilskraft vorkommt; für Kant ist es ebenso eine notwendige Idee wie das Gegenteil; entsprechend hat sich bei uns gezeigt, dass die Kunst ebenso den Wiert des Absoluten verdient wie vermissen lässt; die Begründung hierfür berührt sich mit der entsprechenden Kants: bei diesem fübrt die Genialität, das Exemplarische, von Seiten des Subjekts die Mitteilbarkeit oder Allgemeinheit des 
Werkes, zur Thesis der Antinomie, welche das Übersinnliche behauptet, wäbrend die Originalităt, Einzigkeit, von Seiten des Objekts die Faktizität, zur Autithesis, der Verneinung des Übersinnlichen, zwingt. Kant giebt dieser Antinonie die Lösung (das Anund-für-sich) in der Fassung: das Übersinuliche der Kunst sei die unbestimmte Idee des Übersinilichen als ein Begriff der bloss reflektierenden ästhetischen Urteilskraft (Kr. d. U., 215); d. h. die unbestimmte Idee konstituiert, da sie unbestimmt ist, nicht sich selbst, sondern nur den Wert der Kunst (bei Kant allgemeine Mitteilbarkeit, ästhetischer Gemeinsinn); - wenn ich sie aber als Begriff Gottes setze, so rechtfertigt sich das auch im Sinne Kants darin, dass das Übersinnliche für die Kunst als schöpferischer Geist, intellectus intuitivus, auftritt, wenn auch Kant selbst diesen Begriff erst später einführt.) -

Die Kunst hat so den Begriff des jenseits der Wirklichkeit stehenden, schöpferischen Geistes hervorgebracht; dieser ist Gott als die überwirkliche Individualität, die als Geist aus sich die Welt erzeugt. Gott als der Weltschöpfer ist der abstrakte Begriff des Absoluten, der als Schöpfer ausserhalb seiner Schöpfung steht; er ist die absolute Transscendenz, deren Wirkung die immanente Welt ist. Er ist die absolute Realität, die unendliche Zeugungskraft. Indem Gott alles schafft, ist alles Wirkung von ihm, nichts Grund für ihn. Er ist sich so selbst Grund, d. h. Gott ist die absolut freie Persönlichkeit. Seine Freiheit ist nicht mehr die negative, mit der die Philosophie begann, sondern die positive, d. i. die negative, welche ihren Weg durch die Wirklichkeit gemacht hat. Er ist nicht nur von anderen Bestimmungsgründen frei, sondern auch davon, dass etwas nicht von ihm hervorgebracht wäre; so durchgängig bestimmt Gott alles, was Dasein hat. Er ist das Prinzip der durchgängigen Bestimmung alles Seienden.

Es zeigt sich so, dass der Begriff Gottes nur für das Wirkliche sein Leben hat, nicht aber für sich selbst; Gott ist daher "nur" eine notwendige Idee, seine eigene Wirklichkeit aber ist problematisch. Er ist so nur ein Begriff, und die Notwendigkeit, diesen Begriff aufzustellen, fusst in dem Inbegriff dessen, was bereits hinter uns liegt. Gott ist so der Gegensatz des Begriffes und der Wirklichkeit, d. i. der Freiheit und der Tatsächlichkeit. Indem er als der Begriff des Weltschöpfers gerade diesen Gegensatz vernichten soll, findet er ihn also in sich selbst wieder. 
Gott hält so den ewigen Zwiespalt zwischen der Freiheit und der Wirklichkeit aufrecht, indem seine eigene Freiheit nur als wirkende Ursache des Wirklichen gilt. Dieses Verhältnis von Freiheit und Wirklichkeit ist das ewig Unbegreifliche, und als Träger dieser Unbegreiflichkeit ist Gott der Gegenstand der Religion. Gott selbst aber ist die Lösung des Gegensatzes, indem die Wirklichkeit, als seine Schöpfung, für die Freiheit bestimmt ist. Denn der Werdegang des Wirklichen hinauf zur Freiheit geht durch die innere Reinigung des zur Freiheit Bestimmten, des Menschen als Trägers der sittlichen Werte. In der Religion wird so die Sittlichkeit zum Ideal der Wirklichkeit, um das Reich Gottes auf Erden zu begründen. Das Wirkliche wird so der Freiheit als Gesetzgeberin unterworfen, indem es am Ende der Zeit, am jüngsten Tage, nach gut und böse gerichtet wird. Der Gott der Religion ist so der, der das Gesetz giebt (der ethische Gesetzgeber) und die Welt richtet. Aber das Weltgericht ist nur eine Idee, Gottes Gerechtigkeit ist unwirklich (cf. das Buch Hiob). Die Erde wird nie zum Reiche Gottes werden, und der Riss zwischen dem wirklichen Leben und der himmlischen Heiligkeit klafft auf ewig:

Aber dieses Ewig ist der Triumph des Geistes. Denn die Religion und die Idee Gottes ist nur in der Dualität von Sittlichkeit und Wirklichkeit. So kommt Gott gerade in der ewigen Zweiheit der Welt zu seiner Wirklichkeit; denn dieser Dualismus ist nicht nur ein Begriff, sondern er ist auch da. In der Religion wird so der Dualismus von Wirklichkeit und Sittlichkeit überwunden, indem er als Dualismus notwendig wird. So gelangen wir in der Religion zum Erfassen des absolut Unbegreiflichen. In Gott wird so selbst das Unbegreifliche eben als Unbegreifliches begriffen; in ihm hat alles seine Möglichkeit, weil es in ihm begreiflich wird. Gott aber als das Prinzip der Möglichkeit für alles ist der Weltgeist. Indem Gott (in der Ethikotheologie) die Vereinigung des Übersinnlichen und Sinnlichen begreiflich macht, als einen notwendigen Inhalt der Welt, ist er das höchste Prinzip der Rationalität geworden. Indem er so das Prinzip ist, in dem alles wissbar wird, ist er höher als alles Wissbare, verleibt es sich ein. Alles ist daher in Gottes Geiste, nichts ausser demselben. So verneint Gott jede Transscendenz, er ist selbst die absolute Immanenz, indem alles, auch seine eigene Transscendenz, in der absoluten synthetischen Ein- 
heit seines Selbstbewusstseins .ist. In Gott ist das Transscendente, die absolute Negation des Rationalen, selbst gedacht. Wenn es nichts letzthin Irrationales geben kann, weil es als solches ein Begriff, also wiederum rational ist, so ist das letzthin Rationale dasjenige, in dem selbst der Begriff des letzthin Irrationalen enthalten ist. Das ist aber das Absolute als der Geist, der sich selbst als das Ünbegreifliche begreift. Gott nimmt so den Begriff der transscendenten Realität seiner selbst in sich auf und verneint damit, dass ihm die Realität als das, was ausser dem Begriff stände, zukäme. Gott, als der höchste Vermittler, hat so in sich seine eigene Realität; für Gott, in seinem An-undfür-sich, gilt der ontologische Begriff: Der Begriff Gottes schliesst sein Sein ein. Es giebt nur Eine Welt, die Gottes, die Welt des Geistes. Die göttliche Persönlichkeit ist so der Geist, der seine Realität in sich hat: so ist er Selbstbewusstsein, indem er im Bewusstsein seiner selbst seine Realität besitzt. Die Realität Gottes liegt also in seinem Selbstbewusstsein, im Denken. Der Weltgeist ist der Weltbegriff.

Aber im Denken als dem Begreifen des Unbegreiflichen ist Gott über die Religion, die den Gegensatz des Begreiflichen und Unbegreiflichen festhält, hinaus; das Denken ist so die Selbstverneinung der Religion, und so folgt auf die Philosophie der Religion die des Denkens, d. i. die Logik. Indem Gott als das Unbegreifliche begriffen wurde, ist der Begriff $\mathrm{zu}$ dem geworden, jenseits dessen nichts mehr ist. Der Begriff enthält so die Wahrheit des Gegenstandes als immanentes. Wissen in sich. Das absolute Denken hat den Gegenstand zu seinem unmittelbaren Inhalt, d. h. es ist alles im Denken. Das Reelle ist somit der alleinige Gegenstand des absoluten Denkens, d. h. dieses ist die Erkenntnis von Wirklichkeiten. Im göttlichen Begriffe ist das Ideelle und das Reelle identisch; das Denken zeigt sich so als das Werden der Wahrheit, der Inhalt des Denkens als das Erkannte.

Für die Wahrheit ist selbst die absolute Irrationalität negiert; diese absolute Verneinung gehört aber in den Begriff der Wahrheit hinein, d. h. Wahrheit ist selbst Nicht-Irrationales; indem für die Wahrheit so das Irrationalsein verneint wird, ist sie "nur" Begriff, nicht aber selbst Wirklichkeit. Der absolute Begriff ist so nicht das Wirkliche selbst, sondern Denken des Wirklichen. So aber weiss das Denken sich selbst als das absolut Nichtwirk- 
liche und darin erst weiss es seinen Inhalt ausdrücklich als absolute Wirklichkeit. In der Negation seiner selbst reflektiert der absolute Begriff daher auf die Wirklichkeit seines Inhalts (in der Unwirklichkeit seiner selbst): Der Gegenstand als wirk]icher misst sich an seinem Begriff und entdeckt so in sich den absoluten Widerspruch zwischen der Seite seiner Idealität und der seiner Realität. Der Begriff der Wahrheit findet so in sich wieder den Widerspruch, der sich an Gott zwischen der Rationalität und Irrationalität gezeigt hatte, - aber indem die Wahrheit diesen Gegensatz als solchen weiss, hat sie ihn bereits überwunden und erkennt die Seite der Irrationalität oder Wirklichkeit selbst als ideelle.

Damit gelangt sie zu ihrer Einheit, der absoluten Idee. In dieser sind die Seiten des Widerspruches als Momente bewahrt geblieben; das Rationale des absoluten Begriffes ist die Idee als Begriff ihres Begriffes, das An sich, - das Irrationale die Idee als Begriff ihrer Verwirklichung; und indem der Begriff seine Wahrheit in der Betrachtung seiner Realisation beurteilt, gelangt er zu seinem An und für sich, zu seiner konkreten Idealität. Der Begriff hat so den Wert; das Reelle zu erkennen, und die Wịrklichkeit hat den Wert, als Begriff erkannt zu werden; der Begriff, dessen Wirklichkeit auch im Begriff erkannt und mit inm im Wissen verbunden ist, ist die absolute Wahrheit. (Wir könnten die beiden Momente der Wahrheit auch mit Kantischen Begriffen erläutern: In A priori sind die beiden Seiten der transscendentalen Bedeutung und die der empirischen Anwendung; heben wir diese Begriffe aus dem speziell naturphilosophischen Zusammenhang, in dem sie bei Kant stehen, heraus, so bleibt für uns übrig, dass im Apriori des philosophischen Wissens, d. b. im Wahrheitsbegriff, das Wahre, d. i. der Begriff, seine eine Wahrheit in dem hat, was die philosophische Bedeutung des Begriffes, seine andere in dem, was seine tatsächliche Anwendung ausmacht. - Die Logik als die Wissenschaft von der Wahrbeit giebt so das letzte und höchste Einheitsverhältnis des Ideellen mit seiner Realität und dient für alle anderen Gestalten der Philosophie (die im System vor ihr liegen) als Zielpunkt; der Masstab der Wahrheit liegt so allein im absoluten Begreifen und scheint so für die anderen philosophischen Begriffe nicht in ihnen $\mathrm{zu}$ liegen; es wird sich aber zeigen, dass die Wahrheit keinem Inhalt fremd ist, sodass sie, wie auch der Zielpunkt, so auch der überall vorhandene 
Wert ist und durch sie jeder. Gegenstand der Erkenntnis den Masstab seiner Wahrheit stets in sich trägt.)

Wenn die Wahrheit so die nnendliche Bewegung zwischen dem Begriff als solchem und seiner Realisation, $d$. h. die sich unendlich begrenzende Realität bedeutet, so liegt das unendliche $\mathrm{Be}$ grenzen, das Erkennen selbst, noch nicht in ihr. Die Wabrheit geht also in ihre Negation, die philosophische Wissenschaft, über; die Wahrheit ist für sich nur die leere, absolute Einheit des philosophischen Erkennens-überhaupt; die Philosophie aber ist die Anwendung oder Verwirklichung der Wahrheit. Es ist so der abstrakte Wahrheitswert-überhaupt, von dem ans das philosophische Denken seinen Lauf beginnt; es ist einunddieselbe Wahrheit, welche in allem, was die Philosophie weiss, ihr Leben führt. Die Wahrheit wird so $\mathrm{zu}$ dem abstrakten Inbegriff der Philosophie ohne Inhalte und zeigt sich so als der Begriff des A priori der philosophischen Wissenschaft. Die Wahrheit ist der einzigmögliche Anfang der Philosophie, von dem allein sie für den Begriff ausgehen kann. Aber ebenso zeigt sich, dass dieser Anfang nicht individuell bestimmt ist; er ist überall, wo Philosophie ist. Diese nimmt daher bei jedem ihrer Punkte, überall und nirgends, ihren Anfang.

Die Philosophie ist so die Unendlichkeit der Anfänge ihrer selbst; diese unendliche Anzahl der Anfänge liegt in den unendlichvielen Inhalten der Philosophie; in der Unbegrenztheit ihrer Inhalte wird keiner bevorzugt, sodass jeder Anfang ist. Die Philosophie löst sich so in unendlichviele Individualitäten auf, die jede für sich ihr Leben führer; sie ist so absoluter Pluralismus. Aber selbst darin bleibt sie doch Erkenntnis der Einen Wahrheit, ihre Unendlichkeit liegt so innerhalb der Grenzen ihrer Einheit, läuft daher in sich selbst zurück; die Philosophie gleicht nicht der geraden Linie, sondern dem Kreise, der sich in sich selbst bewegt. Die Philosophie enthält so eben in ihrem absoluten Pluralismus die Kontinuität zwischen ihren Inhalten; diese sind jetzt die ewige Selbstentwicklung der reinen Vernunft, die überall anfängt, weil sie nirgends unterbrochen ist.

Die Philosophie kehrt so zu ihrer Einheit zurück; der absolute Monismus und der absolute Pluralismus gehen ineinander über; die Philosophie ist zugleich Wissenschaft des Einen, der Wahrheit, wie der Unendlichkeit ihrer Begriffe, und sie ist das eine nur wechselseitig im anderen. Sie ist so in der absoluten Totalität 
ihrer selbst und ist damit am Schluss ihrer Tätigkeit angelangt. Die Philosophie bewahrt ihre innere Unbegrenztheit; sie ist in sich unendlich und erweitert sich stetig in sich selbst. Sie hat daher überall und nirgends ihr Ende; wie der Anfang an jedem Punkte war, weil die Philosophie überall Erkenntnis der abstrakten Wahrheit ist, so ist das Ende an jedem Punkte, weil die Philosophie überall Erkenntnis der konkreten Wahrheit ist. Die Philosophie findet ihren Abschluss nur in ihrer eigenen Totalität.

Damit ist sie überall Reflektion auf ihr Ganzes und darin Bewusstsein ihrer inneren Unbegrenztheit, Selbstbewusstsein. Die Philosophie macht sich so selbst zum Gegenstande des Denkens und nimmt die Unbestimmtheit ihres Anfanges und Endes in ihren Begriff selbst auf. Indem diese Unbestimmtheit von ihr verstanden wird, hat sie sie bereits überwunden. Die Philosophie weiss jetzt, wo sie ihren wahren Anfang und ihr wahres Ende zu suchen und auch zu finden hat: im Bewusstsein von sich selbst, in der Philosophie der Philosophie. Sie findet so die Wahrheit in der konkreten Wirklichkeit ihrer selbst und hat die absolute Immanenz des philosophischen Selbstbewusstseins jetzt als Prinzip; sie hat

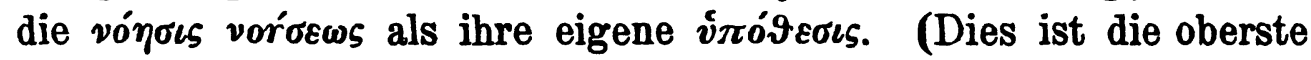
synthetische Einheit des Selbstbewusstseins, nämlich des philosophischen, - welches ebenso zur Philosophie gehört wie jedes andere, ja noch viel inniger. Man kann aber das philosophische Selbstbewusstsein nicht gleichsam verdecken und sehen, was dann übrig bleibt; es wäre nichts; denn alles ist nur im Wissen des Philosophen von sich selbst, welches wir das Begreifen nennen. Das Prinzip der Philosophie ist das der Immanenz - immanent ist aber nur das Denken, das seine eigenen Inhalte begreift, $d . h$. denkt - und jeder Idealismus ausser diesem absoluten ist noch in dem Glauben befangen, als ob die Philosophie im Erkannten sich selbst als Erkennenden vergessen könnte. Solange das Selbstbewusstsein (das Denken) nicht als Substanz alles philosophischen Wissens begriffen ist, muss immer noch irgend ein Transscendentes in die Philosophie hineinkommen, welches sie zur Metaphysik im schlechten Sinne machen muss, - sei dies Transscendente nun ein Sollen oder das Irrationale oder der Wert an sich. Es giebt in der Philosophie kein anderes Primat, weder eins des Willens noch eins des Wertes, als das Primat der Philosophie selbst. - Der Idealismus, solange er nur als Erkenntnistheorie der Erfahrung, des Endlichen auftritt (wie heutzutage ausschliesslich), hat ganz 
Rucht, wenn er bemerkt, dass er besser tat, Ausdricke wie Bewasstsein, Denken, Erkennen fallen zu lassen und die Wahrheit gleichsam nur anzuschauen als dasjenige, was Wert hat (System der Werte); aber solange der Philosoph nicht bemerkt, dass er vor der Erkenntnis dessen, was Natur, Geschichte, Kunst, Moral u. s. w. ist, sich darauf besinnen muss, was Philosophie selbst ist, ist sein Denken ohne Methode, daher nicht Wissenschaft der Wahrheit, sondern - selbst in der breitesten Ausführung - Aperçu. Er wird dann auch die so einfache und so schwerwiegende Entdeckung machen, dass die Unterscheidnngen, welche er zwischen: entweder Wert und Sein oder Notwendigkeit und Faktizität, zwischen Denken und Denkfremden macht, nicht zutreffend sind, dass das Sein zwar etwas Spezifisches bedeutet, aber dasjenige, das den Wert des Seins hat, dass das Faktische dasjenige ist, dass notwendigerweise faktisch ist, dass das Sinnfremde dasjenige ist, das den Sinn des Sinnfremden hat; und sodann wird er sich über der Dualität seiner Distinktionen zar Einheit des Prinzipes erheben, das seinen Distinktionen ja erst dasjenige verleiht, durch das sie zu begreifen sind; und dieses Prinzip ist dieses, dass alles im Reich des Wertes ist, auch das Sein, alles in der Notwendigkeit, auch das Faktische, alles im Denken, auch das Denkfremde.)

Indem die Philosophie sich sich selbst zum Prinzipe macht, ist der Begriff des Prinzipes ein transscendentallogischer, d. h. ein philosophischer, ein solcher, der eine Beziebung auf Inhalte in sich hat. Das Selbstbewusstsein geht von der einfachen Identität seiner selbst zur unendlichen Inhaltlichkeit über. Das philosophische Denken weiss sich so als das Denken, dem der gedachte Inhalt entspringt; der philosophische Begriff hat seinen Umfang auch zu seinem Inhalt, - weil ja alles in der Philosophie im denkenden Bewusstsein ist. Das Selbstbewusstsein oder die Philosophie weiss sich so als die Art und Weise, wie die Inhalte der Philosophie hervorgebracht werden, d.h. als philosophische Methode. Das Selbstbewusstsein ist daher nicht nur die ruhige Versunkenheit in die Identität seiner selbst, sondern hat ebensosehr mit unerbitterlicher Aufmerksamkeit sein Auge auf die Schritte des produzierenden Denkens gerichtet. Indem das Denken die Art und Weise seines Denkens ausieht, drückt es ein absolutes Misstrauen, eine absolute Skepsis aus; die Methode des Sichselbstüberwachens entdeckt den dialektischen Widerspruch des Denkens (den Einwurf 
des Relativisten) und begreift ihn, ihn so überwindend. Die dialektische Methode ist so die Seite der Negativität aller Philosophie; die Methode des Philosophierens ist die unendliche Unruhe des Denkens, das das Prinzip verloren hat.

Aber in der dialektischen Reflektion ist sich doch das Denken seiner in der vernichtenden Beziehung auf den Inhalt bewusst; es ist so Selbstbewusstsein, wahrt in jedem Falle das Prinzip, ist Denken des Denkens. Das Gedachte ist ihm jetzt nicht schlechter als das Denken; indem die Philosophie ihre Begriffe gegen den Feind (Skepsis) mit dessen eigenen Waffen verteidigt hat, hat sie alle ihre einzelnen Inhalte in das Bewusstsein von sich selbst aufgenommen. Das philosophische Selbstbewusstsein ist jetzt nicht nur das Bewusstsein von sich selbst, sondern aueh von sich als der Ursache seines Wissens; es hat so die methodisch hervorgebrachten Inhalte in der Einheit seines Bewusstseins vereinigt, d. h. weiss sie als System. Hierin ist die Philosophie als Prinzip, das den wechselseitigen Bedeutungszusammenhang der philosophischen Einzelbegriffe weiss. Der Schlussstein des Systems der Philosophie ist so der Systembegriff selbst, das An-und-für-sich der Philosophie der Philosophie und überhaupt der Logik. (Andere werden dies die Erkenntnistheorie der Philosophie nennen, - wobei nur dieser Terminus den Mangel hat, nicht anzuzeigen, dass die Philosophie über sich selbst keinen anderen Richter haben kann, ohne dass dieser nicht selbst wieder Philosoph wäre. Es ist der Systembegriff, mit dem die Philosophie über solche Gedanken, als könnte sie Grenzen der Erkenntnis haben, hinaus ist; nur die Erfahrung hat Grenzen, und wenn die Geschichte des Idealismus mit dem Ziehen dieser Grenzlinien begonnen hat, so hat eben die Kantische Philosophie noch die Vermischung in sich, die Begründung der Erfahrung als leine solche der spekulativen Vernunft erscheinen zu lassen, während diese das ist, von dem das Erfahrungswissen begrenzt wird; in dem Wort Kritik der reinen Vernunft dürfen wir heute keinen genetivus objectivus, sondern nur einen genetivus subjectivus sehen. Die Hegelsche Naturphilosophie wiederum hat, wenn in ihr der Organismusbegriff als An-und-für-sich-begriff der Natur auftritt, einen verbildeten Naturbegriff und hat fälschlich die Meinung gehabt, als müsste der Begriff des philosophischen Wissens den eines empirischen Wissens gänzlich aufheben, - während es in Wahrheit der philosophischen Wahrheit nichts anhaben kann, dass sie im Begriff 
des Erfahrungswissens ein solches Wissen anerkennt, das nie zu seinem Eude, also auch nie zur "unbedingten" Wahrheit kommt, deshalb aber nit dem philosophischen Wissen nicht einmal in der Gemeinschaft eines genus proximum steht. Das System der Philosophie hat zwar nicht nur die Unschädlichkeit, sondern auch die Notwendigkeit des Erfahrungsbegriffes zu zeigen, wie es in den vorliegenden Andeutungen eines Systems anch versucht worden ist. - Die Hegelsche Philosophie hat also die ununterdrückbare Wahrheit, die Philosophie selbst zum Objekt der Spekulation zu machen, und dies nicht nur so nebenbei, sondern in der Erkenntnis, dass dies die Wurzel des philosophischen Wissens ist, - and so hat sie den klaren Begriff aufgestellt, dass das philosophische Selbstbewusstsein das Prinzip der Philosophie ist und dass die dialektische Methode diesem Prinzip seine Wirklichkeit giebt, indem sie es zum System führt. Das Prinzip wird so zur Methode, und die Methode weiss sich als Prinzip - im System. - Man drückt den Wert des Systems wohl so aus, dass man sagt, alles sei im System an seinem Platze, das Einzelne hätte nur im Zusammenhang des Ganzen seine Wabrheit; dieser harmlose Ausdruck hat zwar durchaus Recht, aber er drückt sich noch unklar aus. Wie ist denn das Einzelne im Ganzen möglich, ohne dieses zu zerstücken oder selbst in ihm unterzugehen? Nur so, dass das Einzelne eben zwar seine Wahrheit hat, aber in dieser sich in einem Widerspruch verwickelt sieht, der in Übergang zu einer anderen Wahrheit seine Lösung findet. Nur so ist es möglich, dass es nur Eine Wahrheit und doch viele Begriffe giebt, nur so, dass die Natur Mannigfaltigkeit und zugleich Erkennbares bedeutet, usw. Im System erst hat also das Einzelne seine durchgängige Bestimmtheit, - und deshalb ist eine systemlose Philosophie nur eine Vorstufe. Wir aber, die wir es historisch hinter uns stehen haben, dass Philosophie ohne System Nichts ist, baben es leicht, die Vorstufen zu überspringen; aber es ist wahr, wir müssen dies auch ausführen).

Im System der Philosophie hat die Erkenntnis Gottes ihr Dasein; aber alles Dasein ist an sich betrachtet noch zufällig, es ist dann ebenso noch zufällig, welches das System ist; es kann so sein, es kann anders sein. Zwar ist sein Sosein im durchgeführten System unantastbar, aber gleichwohl nicht begreiflich und daher nicht rational notwendig. Erst in der Geschichte der Philosophie kommt das Dasein des Systems zu seiner Not- 
wendigkeit, indem sein Ideal das Ziel der Entwicklung darstellt. Die Geschichte der Philosophie ist deshalb die Offenbarung des Geistes genannt worden; jede Philosophie wird so gerechtfertigt und zugleich für verbesserungswürdig erklärt. Sobald aber die Philosophie sich diese Bedeutung ihrer Geschichte zum Begriff geführt hat, ist sie wahrhaft Wissenschaft geworden; sie hat jetzt die mögliche Entwicklung in einer Geschichte, deren Ziel ihren Begriff erst konstituiert hat. Kant hatte sich zuerst das Ziel gesetzt, die Philosophie zur Wissenschaft zu erheben, und Hegel hat dies zuerst ausgeführt. Die Hegelsche Philosophie konnte sich daher mit Recht als Ende wie andererseits als Vorstufe zu weiteren Entwicklungen des Denkens bezeichnen, wie sie letzteres durch die Tat bewies, in dem immer eindringlicheren Denken, mit dem sie sich durch die Hand ihres Schöpfers selbst veränderte. - Auch dieser Aufsatz giebt ein System, das in die historische Reihe gehört, wenn auch nur im Grundrisse: teils dadurch, mehr aber noch durch die trostlose Knechtschaft, in der die Philosophie der Zeit sich gefällt, und von der auch dieser Aufsatz sich nicht wahrhaft hat befreien können, kommt er in einer so provisorischen Gestalt zu Stande, wie er tatsächlich tut. Durch sein Anknüpfen an das System der Kantischen Philosophie und die in demselben aufgestellte Kategorientafel hat er sich Werkzeuge des Denkens erwählt, die nicht in wahrhaft historischem Geiste, d. i. in dem Sinne benutzt werden, in dem die philosophiegeschichtliche Entwicklung jene Gestalten mit dem heutigen Tage notwendig verbunden hat. Es muss daher dem Aufsatz die Eigenschaft, ein System zu begründen, aberkannt werden; wie könnte sonst ein Teil des Ganzen, wie etwa die Geschichte, so notdürftig neben einem anderen, wie der Natur, behandelt werden, andere Begriffe, wie Organismus, Individualität, gänzlich übersprungen sein, wenn das nicht durch die selbsterwählte historische Gebundenheit veranlasst worden wäre? So hat hier das Anknüpfen an Vergangenes wohl fördernd, nicht aber befreiend gewirkt, wenn ich diesen Erfolg nicht dem Anknüpfen an die Methode Hegels zuschreiben darf. So mag es verständlich sein, wenn ich das Gewicht bei diesem Aufsatz jetzt nachher, wo ich ihn zu beurteilen habe - nicht auf seine einzelnen Inhalte, sondern auf seinen Geist im allgemeinen, seine Richtung lege. Indem hier zum erstenmal die Philosophie wieder als bewusst systematische erscheint, hört sie auf, Schleppträgerin 
empirischer Wissenschaften zu. sein, und glaubt bewiesen zu haben, dass die Vereinigung von Kant und Hegel möglich and zeitgemäss ist. -

Zum Schluss will ich noch einmal auf Anfang und Titel des Aufsatzes zurückgreifen: Kategorientafel und System? Statt aller Antwort mag hier, als Leitfaden für den Leser, nachstehende Tafel abgedruckt werden, der ich nur folgende Bemerkung hinzufüge: wenn jemandem das, was er Anfangs zu finden glaubte, nicht geworden ist, nämlich eine endliche Lösung der Kategoriendeduktion, so hoffe ich, dass er dafür anderes gefunden hat, was er ursprünglich nicht erwartete; gewiss gehört aber diese Inkongruenz von Titel und Ausführung zu den vielerlei Mängeln dieses Systemversuches; deshalb sei mir auch der Abdruck der Tafel verziehen, der an sich ungehörig wäre, wenn ihn nicht die gedrängte Form meiner Ausführungen ratsam erscheinen liesse. Und überhaupt dürfte ich es eigentlich in der Durchführung meiner Problemstellung (im Gegensatz zu deren Aufstellung) selbst bereits zum sichtbaren Ausdruck gebracht haben, dass die Kategorien letzthin der Philosophie nicht so äusserlich inhärieren, wie es in der folgenden Tafel erscheint.

\begin{tabular}{|c|c|c|c|c|}
\hline Kategorien & Ethik & Wirklichkeit & (Kunst) & Absolutes \\
\hline Qualität & I. Freiheit & II. Gegenstand & III. Kunstwert & II. Wahrheit \\
\hline $\begin{array}{l}\text { Realität } \\
\text { Negation } \\
\text { Limitation }\end{array}$ & $\begin{array}{l}\text { Gut } \\
\text { Böse } \\
\text { Heilig }\end{array}$ & $\begin{array}{l}\text { A posteriori } \\
\text { Apriori } \\
\text { Affin }\end{array}$ & \begin{tabular}{|l} 
Schön \\
Erhaben \\
Ästhetische \\
$\quad$ Idee
\end{tabular} & $\begin{array}{l}\text { Begriff } \\
\text { Wirklichkeit } \\
\text { Absolute Idee }\end{array}$ \\
\hline Quantität & III. Gesetz & I. Wissen & II. Kunstwerk & III.Philosophie \\
\hline $\begin{array}{l}\text { Einheit } \\
\text { Vielheit }\end{array}$ & \begin{tabular}{|l} 
Sittengesetz \\
Sitte \\
Recht
\end{tabular} & $\begin{array}{l}\text { Ist } \\
\text { Mannigfaltig- } \\
\quad \text { keit } \\
\text { Erfahrung }\end{array}$ & $\begin{array}{l}\text { Form } \\
\text { Inhalt } \\
\text { Individualitat }\end{array}$ & $\begin{array}{l}\text { Anfang } \\
\text { Entwicklung } \\
\text { Ende }\end{array}$ \\
\hline Relation & \begin{tabular}{|l} 
III. Gesetz der \\
Freiheit
\end{tabular} & $\begin{array}{l}\text { III. Wissen des } \\
\text { Gegenstan- } \\
\text { des }\end{array}$ & I. Kunst & $\begin{array}{l}\text { IV.Philosophie } \\
\text { der Philoso- } \\
\text { phie }\end{array}$ \\
\hline Substanz & $\begin{array}{c}\text { Individual- } \\
\text { gesetz }\end{array}$ & $\begin{array}{l}\text { Phänomenali- } \\
\text { tät }\end{array}$ & Originalität & $\begin{array}{l}\text { Prinzip der } \\
\text { Philosophis }\end{array}$ \\
\hline Kausalităt & Gesellschaft & $\begin{array}{l}\text { Unendlicher } \\
\text { Progressus }\end{array}$ & Genialität & $\begin{array}{l}\text { Methode der } \\
\text { Philosophie }\end{array}$ \\
\hline Gemeinschaft & Staat & $\begin{array}{c}\text { Empirische } \\
\text { Wissenschaft }\end{array}$ & $\begin{array}{r}\text { Kunstsubjekt } \\
\text { und -objekt }\end{array}$ & $\begin{array}{l}\text { System der } \\
\text { Philosophie }\end{array}$ \\
\hline
\end{tabular}


Kants Kategorientafel etc.

\begin{tabular}{l|l|l|l|l}
\hline Modalitat & $\begin{array}{r}\text { IV.System der } \\
\text { Wirklichkeit }\end{array}$ & $\begin{array}{l}\text { I. System des } \\
\text { Absoluten }\end{array}$ \\
\hline $\begin{array}{l}\text { Moglichkeit } \\
\begin{array}{l}\text { Dasein } \\
\text { Notwendig- } \\
\text { keit }\end{array}\end{array}$ & $\begin{array}{l}\text { Welt } \\
\text { Geschichto } \\
\text { Kunst }\end{array}$ & $\begin{array}{l}\text { Religion } \\
\text { Logik } \\
\text { Geschichtoder } \\
\text { Philosophie }\end{array}$ \\
\hline
\end{tabular}

Red. Anm. Durch ein Versehen sind einige Druckfehler stehen geblieben, die hier nachträglich verbessert seien:

S. 392, Z. 2 v. o. anstatt $n^{z u^{\prime \prime}}$ lies $n^{z u}$ eigenen"
$n$
Z. 5 v. 0
"origonalen ${ }^{\mu}$ lies ${ }_{n}$ originalen ${ }^{\mu}$

S. 394, Z. 8 จ. u. $\quad$ " Begriff-überhaupt" lies "Begriff-überhaupt ${ }^{4}$
$n$
Z. $5 \vee$ u. $"$
„Vollkommen“ lies "vollkommen". 